\title{
OS DETERMINANTES DA QUEDA DA DESIGUALDADE DE RENDA NAS REGIÓES BRASILEIRAS ENTRE 2001 E 2015
}

\section{Marina Guazzelli Saad (1)}

(D) https://orcid.org/0000-0002-4910-7496

\section{Adriana Bruscato Bortoluzzo}

(D) https://orcid.org/0000-0003-2872-031X

Naercio Aquino Menezes Filho ${ }_{3}$

(D) http://orcid.org/0000-0003-1241-6188

\section{Bruno Kawaoka Komatsu (1)}

\author{
(D) http://orcid.org/0000-0002-7731-3422 \\ (1) Insper, São Paulo - SP, Brasil. E-Mail: marinags@al.insper.edu.br \\ (2) Insper, São Paulo - SP, Brasil. E-mail: adrianab@insper.edu.br
}

(3) Insper e Faculdade de Economia, Administração e Contabilidade da Universidade de São Paulo (FEA-USP), São Paulo, - SP, Brasil. E-mail: NaercioAMF@insper.edu.br

(4) Insper, São Paulo - SP, Brasil. E-mail: BrunoKK@insper.edu.br

DOI: $10.1590 / 3510313 / 2020$

\section{Introdução}

Nos últimos anos, os programas sociais de transferência de renda promovidos pelo governo federal têm ganhado força e atenção da população brasileira. Esse tipo de transferência de renda tornou-se conhecido essencialmente após a criação do Programa Bolsa-Família (PBF), em 2003, pelo qual as famílias com renda extremamente baixa recebem uma transferência do governo como um auxílio financeiro, de modo a permitir sua maior inserção na sociedade. O aumento da renda dos menos afortunados garante melhores condiçóes de vida para esses indivíduos e suas famílias, reduzindo as diferenças sociais no país.

Programas, como o PBF, foram criados com o objetivo de reduzir a pobreza, grave problema no Brasil

Artigo recebido em: 30/11/2018

Aprovado em: 17/10/2019 e pauta constante nas políticas públicas nacionais, e também costumam gerar efeitos sobre a desigualdade (Ferraz, 2008; Tavares et al., 2009; Rocha, 2011; Peña et al., 2015). O Brasil está entre os países com os maiores níveis de desigualdade no mundo (Barros, Carvalho e Franco, 2007, p. 8). Segundo dados da pesquisa World Development Indicators, do Banco Mundial (World Bank, 2016), os 10\% mais ricos do Brasil recebem uma renda mais de 40 vezes maior do que a apropriada pelos $10 \%$ mais pobres, enquanto esta diferença entre ganhos é igual a 18 vezes nos Estados Unidos da América, e apenas 10 vezes, na França e no Canadá. Na comparação com outros países latino-americanos, o Brasil é mais desigual do que Chile, Argentina, Peru e México, de acordo com relatório da Organização para a Cooperação e Desenvolvimento Econômico (OCDE, 2015).

Apesar do elevado nível de desigualdade de renda no Brasil, sua evolução entre 2000 e 2015 foi negativa e acompanhada por um crescimento do PIB 
e de melhoria nas condições do mercado de trabalho. O índice de Gini, por exemplo, diminuiu 13,6\%, de 2001 a 2015 no Brasil, de acordo com dados da Pesquisa Nacional por Amostra de Domicílios (PNAD). Entretanto, a partir do segundo trimestre de 2014, o Brasil entrou em uma das mais longas recessóes de sua história, tendo durado 11 trimestres e reduzido o PIB brasileiro em 8,6\% (CODACE, 2017). Refletindo esse contexto, houve, entre 2014 e 2015, uma queda de $5 \%$ dos rendimentos reais (IBGE, 2016), enquanto o índice de Gini da renda domiciliar per capita permaneceu praticamente constante. Como comparação, a redução anual média, entre 2001 e 2014, havia sido de 1,1\%. Os efeitos desta recessão sobre o mercado de trabalho foram amplamente documentados, porém seus impactos sobre a desigualdade de renda ainda não foram estabelecidos em detalhes. Em especial, não está claro qual é o papel dos programas de transferência de renda, nos momentos de recessão econômica.

Há dúvidas sobre a eficácia da aplicação dos programas, devido aos diversos efeitos que eles geram no comportamento dos indivíduos e na economia como um todo, sendo possível que alguns desses efeitos sejam adversos à desigualdade. Um exemplo seria um efeito de substituição desses benefícios em relação ao trabalho (Brito, 2011). Existem, ainda, questionamentos sobre a forma como os programas são distribuídos entre os indivíduos, se eles são realmente eficientes, e se não existe corrupção envolvida nessa distribuição. Corrêa (2016) mostra que existe ganho de votos nas regióes mais pobres, e perda de votos nas regióes mais desenvolvidas, para os candidatos à Presidência que investiram nos programas de transferência de renda. Em contextos de recessão econômica, é possível que a redução do número de ocupados faça com que a quantidade de beneficiários aumente e que os efeitos sobre o comportamento individual, documentados por Brito (2011), contribuam para uma recuperação mais lenta da crise econômica, com menor oferta de trabalho; ou, ao contrário, que a renda fornecida pelo programa mantenha mercados locais em funcionamento, apesar da redução da demanda.

O presente estudo tem como objetivo primordial verificar como os programas de transferência de renda do governo afetaram a desigualdade no Brasil, nos últimos quinze anos, analisando também o período mais recente, que cobre o início da recessão na economia brasileira. Para isso, será realizada uma decomposição do índice de Gini, seguindo Hoffman (2006), para analisar como as diferentes fontes de rendimento dos indivíduos influenciaram a redução da desigualdade. Nossa principal contribuição, relativamente aos estudos anteriores, reside em realizar a análise com uma série longa de dados, dividir a análise em subperíodos, e comparar diferentes regiôes do país. Dado que os programas já estão ativos há um período considerável de tempo, será possível analisar seus efeitos sobre a desigualdade no curto e no longo prazo. Será que os programas de renda se esgotam com o passar dos anos, gerando efeitos adversos na sociedade? Como a contribuição dos programas de transferência de renda se comporta em períodos de crescimento e de recessão econômica? Será que os efeitos dos programas divergem em diferentes localidades, com diferentes níveis de desigualdade? Existem padrōes de evolução da desigualdade entre as unidades federativas?

Buscando responder a estas questóes, este artigo se divide em cinco seçóes, incluindo a presente introdução. Na segunda seção, fazemos um levantamento da literatura com a qual dialogamos. $\mathrm{Na}$ terceira seção, descrevemos a metodologia e a base de dados. Apresentamos os resultados na seção 4 , e as conclusões, na seção 5 .

\section{Revisão Bibliográfica}

$\mathrm{Na}$ literatura internacional, a evolução da desigualdade de renda está geralmente associada a fatores como, por exemplo, o aumento da proporção de indivíduos empregados no país, ou mudanças no cálculo da aposentadoria, e não a programas de transferência de renda. Athanasopoulos e Vahid (2003) analisaram a evolução da desigualdade de renda na Austrália, entre os anos de 1986 e 1999, e verificaram que a elevação da desigualdade foi gerada essencialmente por variaçóes na renda dos indivíduos já aposentados, o que sugere que porçôes da renda diferentes do salário do trabalho dos indivíduos, como a aposentadoria, foram responsáveis pela variação 
na desigualdade. Além disso, tal elevação ocorreu principalmente nas áreas metropolitanas.

As mudanças na desigualdade de renda, para o grupo étnico indígena da Nova Zelândia, chamado Maori, foram analisadas por Dixon e Maré (2007), no período de 1997 a 2003 . Houve uma queda na desigualdade de renda para os Maori, decorrente da migração de indivíduos para o mercado de trabalho e do acesso à educação. Por sua vez, Balvociute (2014) fez uma comparação de índices entre 2005 e 2011, para os países da União Europeia, buscando estimar as mudanças na desigualdade de renda, além de identificar a situação da Lituânia nesse contexto. Para isso, utilizou o coeficiente de Gini e a curva de Lorenz e observou que a disparidade nos níveis de desigualdade de renda existente entre os países estudados diminuiu, em média, tornando-os mais homogêneos.

Os estudos internacionais que abordam a desigualdade social se diferenciam dos elaborados no Brasil, uma vez que o sistema de transferência de renda brasileiro é bastante peculiar. Não há, no mundo, um programa de governo que busque reduzir a pobreza, tão fortemente, como o Programa Bolsa Família (PBF), tornando, assim, o tema muito mais presente na literatura nacional. A maioria dos estudos nacionais procura compreender como as diferentes fontes de renda e, principalmente, como os programas de transferência de renda brasileiros, afetam a desigualdade de renda, tendo inclusive estudos focalizados no Programa Bolsa Família e no seu impacto sobre a desigualdade e a pobreza (Ferraz, 2008; Tavares et al., 2009; Rocha, 2011).

Peña et al., 2015, por exemplo, mostraram que a implementação do PBF provocou um melhor índice de mobilidade social e tendência de convergência mais rápida para um melhor nível de renda real. Marques (2013) fez uma completa descrição da aplicação do Programa Bolsa Família no país e, ainda, comparou-o com a estrutura de transferência de renda realizada na Argentina, concluindo que, diferentemente desse país, o Programa Bolsa Família possui um componente sem condicionalidades em sua aplicação, o que reduz diretamente o nível de desigualdade de renda do país. Carneiro, Alvim e Bagolin (2012) estudaram como o Programa Bolsa Família contribuiu para a evolução da desigualdade, no período de 2004 a 2009, incluindo o número de beneficiados pelo Programa Bolsa Família e o valor total dos benefícios em regressóes com dados em painel, mostrando que os programas não só elevam a renda, como há também efeitos nos padróes alimentares, de educação e de saúde.

Por sua vez, há estudos que buscam entender se essa evolução da desigualdade pode ter sido originada por outros fatores, além das fontes de renda. Ferreira e Cruz (2010) identificaram que políticas que melhoram nível de emprego e produtividade do trabalho podem apresentar resultados mais eficazes na redução da desigualdade, quando comparadas com políticas redistributivas de renda. Além disso, os autores mostram que facilitar o acesso à educação de qualidade aos menos favorecidos pode reduzir a desigualdade de renda, especialmente nos locais que apresentam maior desigualdade inicial. Melo e Monte (2014) mostram que o PBF não foi o principal impulsionador da queda da desigualdade, apesar de ter um efeito positivo sobre o índice de Gini. Segundo eles, a desconcentração das rendas do trabalho do homem, da seguridade social e do trabalho da mulher foram os grandes responsáveis pela queda da desigualdade. Hoffmann (2017) chegou a conclusóes similares, mostrando que o salário dos funcionários públicos estatutários e as aposentadorias e pensóes oficiais foram as parcelas do rendimento que impulsionaram a mudança da trajetória da desigualdade, a partir de 2014.

Com o objetivo de examinar a determinação de cada fonte de rendimento, diversos autores buscaram analisar a progressividade e a regressividade das rendas, verificando como cada fonte de renda, por sua natureza, impacta de forma positiva ou negativa na desigualdade de renda. Hoffman (2009) diferenciou as parcelas de rendimento regressivas, caracterizadas por aumentar o grau de desigualdade da distribuição de renda da população, das progressivas, que contribuem para a diminuição da desigualdade da distribuição. Segundo o autor, quase $50 \%$ da redução do Gini, no período de 2001 a 2007, ocorreram através dos rendimentos do trabalho privado. Já a contribuição da parcela que inclui os programas de transferência, como o Bolsa Família, foi de aproximadamente 25\% na redução da desigualdade, de 2001 a 2004, mas esse efeito diminuiu de 2004 a 2007, passando a ser de apenas $10 \%$. 
Hoffmann (2013) mostra, ainda, que há particularidades nos rendimentos e nos impactos desses rendimentos sobre a desigualdade em diferentes regiōes e estados brasileiros, assim como em regiōes com diferentes atividades econômicas. Um exemplo disso encontra-se em Hoffmann e Oliveira (2012), que mostram que o setor da agricultura apresentou um comportamento diferenciado dos demais setores de atividade, pois nele os determinantes para a queda da desigualdade são diferenciados. Para o Brasil como um todo, 21\% da redução da desigualdade, de 2003 a 2009, foi resultado dos programas de transferência, sendo que, para as regióes agrícolas, esse número chegou a $46 \%$. Para os rendimentos de empregados, por outro lado, as porcentagens foram de 51\% para o Brasil, e de $10 \%$ para as regióes agrícolas. O setor agrícola também foi destacado por Jesus e Hoffmann (2016), que mostram que entre os domicílios não agrícolas, cerca de $61 \%$ da reduçáo do Gini estava associada ao rendimento do trabalho, e 18\% a transferências do governo. Esses valores foram de $23 \%$ e $64 \%$, respectivamente, para o setor agrícola.

Outros estudos mostram também a importância relativa dos programas de transferências sobre a desigualdade, em comparação com outras fontes de renda, examinando separadamente áreas rurais e urbanas. Bertoni Neto, Inforzato de Souza e Ferreira (2013) observaram que a desigualdade permaneceu mais elevada nas áreas urbanas, para todos os anos, sendo que a renda do trabalho contribuiu para reduzir a desigualdade nessas áreas, enquanto elevou a desigualdade nas áreas rurais.

Ainda sobre áreas rurais, Helfand, Rocha e Vinhais (2009) mostram que a queda da pobreza rural, entre 1992 e 1998, foi resultado apenas do crescimento da renda devido ao aumento da previdência e pensóes, enquanto no período de 1998 a 2005, mais da metade dessa queda foi consequência da maior igualdade de renda no país, gerada essencialmente pelo aumento da renda do trabalho. Os autores concluíram, ainda, que, no Brasil rural, as fontes de renda alternativas, que incluem o PBF, foram responsáveis por $44 \%$ da redução da desigualdade de renda. Em suma, a maior parte dos estudos mostra que a queda da desigualdade nas áreas urbanas e não-agrícolas parece ter sido mais influenciada pela renda do trabalho, ao passo que nas áreas agrícolas e rurais os programas de transferência de renda parecem ganhar destaque.

Hoffman (2006) utilizou dados da Pesquisa Nacional por Amostra de Domicílios (PNAD), de 1997 a 2004, para avaliar as parcelas do rendimento domiciliar que mais contribuem para as alteraçóes na desigualdade de renda, sendo elas: rendimento do trabalho; aposentadorias e pensóes: oficiais e outras; doaçóes, aluguéis e a parcela definida pela PNAD como "outros rendimentos", que inclui juros, dividendos e os programas de transferência de renda. Concluiu-se que $28 \%$ da redução da desigualdade foi efeito das mudanças na parcela "outros rendimentos", que inclui os programas do governo, como o Bolsa Família. Porém, a maior parte da redução foi gerada pelo rendimento de todos os trabalhos; isto é, 65,5\% da redução do Gini. Dentre as regiôes, o efeito dos programas foi muito importante no Nordeste, onde chegou a ser responsável por quase $66 \%$ de redução do Gini, mostrando a importância de distinguir a análise para as diferentes regiōes brasileiras. Analisando um período distinto, de 1995 a 2012, Hoffmann (2014) chegou a conclusões distintas, observando que o rendimento do trabalho foi responsável pela redução de $50 \%$ do Gini.

O diferencial do estudo de Soares et al. (2006) foi a decomposição da parcela "outros rendimentos", contida na PNAD, permitindo separar as rendas provenientes do Benefício de Prestação Continuada (BPC $)^{1}$ de outros programas de transferência e juros, de forma a eliminar uma restrição desses dados. Foi observado que os programas de transferência contribuíram para a redução da desigualdade, entre 1995 e 2004, tendo o PBF sido responsável por 21\% da queda observada no índice de Gini, e o BPC, por $7 \%$ dessa queda. Procedimento semelhante de decomposição dos rendimentos foi utilizado por Barros, Carvalho e Franco (2007), com dados da PNAD, de 2001 a 2005, para identificar o impacto na desigualdade de renda de quatro fatores: o grau de associaçáo de uma fonte de renda com as outras; a expansão de cobertura de uma fonte de renda; o valor médio do benefício recebido entre os receptores; e a desigualdade entre os receptores. Dentre as rendas não derivadas do trabalho, os autores observaram que as aposentadorias e pensões foram as que mais 
contribuíram para a redução da desigualdade (26\%), seguidas pelo Bolsa Família (12\%) e, depois, pelo Benefício de Prestação Continuada (11\%). Araujo e Morais (2014) constataram que, de 2002 a 2011, a diminuição da concentração de cada parcela de renda foi o principal fator para a redução da desigualdade, sendo que as mudanças da participaçáo de cada fonte de renda no rendimento total tiveram pouco efeito nesses resultados. A parcela mais relevante foi o rendimento dos trabalhos, que impactou em $56 \%$ a reduçáo do Gini, enquanto a parcela de "outros rendimentos", que incluiu os programas de transferência, foi responsável por $21 \%$ dessa redução, com efeito especialmente relevante na regiáo Nordeste.

Apesar de haver, no Brasil, uma extensa literatura sobre o tema em questáo, mostrando que os programas de transferência de renda contribuíram realmente para a redução da desigualdade, há divergências quanto ao papel específico das transferências de renda, dependendo do período analisado. Neste sentido, o presente artigo procura contribuir com a literatura por meio da análise de um período mais abrangente do que os estudos anteriores, com a divisão dos dados em subperíodos permitindo comparar os resultados entre momentos de crescimento e de recessão econômica e a análise de diferentes estados e regióes do Brasil, de forma a compatibilizar os resultados encontrados.

\section{Metodologia}

Nesta seção, serão apresentadas brevemente as técnicas utilizadas no estudo, a saber o índice de Gini, como medida de desigualdade de renda, e a decomposição do mesmo, além da descrição da base de dados.

\section{Indice de Gini como Indicador de Desigualdade}

A grande maioria dos estudos mencionados, na seçáo 2, utilizou o índice de Gini como medida de desigualdade, e aqui faremos o mesmo, por uma questão de comparabilidade com os resultados anteriores. Para os efeitos do presente estudo, o Gini foi calculado levando em consideraçấo o rendimento domiciliar per capita, medido a partir de algumas fontes de interesse (ver seção 3.2). O cálculo do índice de Gini é feito com base na curva de Lorenz, que descreve como a proporção acumulada da renda varia em relaçáo à proporção acumulada da populaçáo, estando os indivíduos ordenados pelos valores crescentes da renda domiciliar per capita; sendo $\beta$ a área entre o eixo das abscissas e a curva de Lorenz, e $\alpha$ a área entre a mesma e a reta de $45^{\circ}$, de modo que $\beta+\alpha=0,5$. Quanto mais próxima da reta de $45^{\circ}$ estiver a curva, ou seja, quanto maior a área de $\beta$, menor será a desigualdade de renda dessa população. Quanto menor a área de $\beta$, maior a desigualdade de renda. O índice de Gini é a relação entre a área $\alpha \mathrm{e}$ a área do triângulo representado por $\alpha+\beta$, ou seja:

$$
G=\frac{\alpha}{\alpha+\beta}=1-2 \beta
$$

$\mathrm{O}$ índice pode assumir valores entre $0 \mathrm{e} 1$, sendo que quanto mais próximo de 1 for esse valor, maior será a desigualdade de renda entre os indivíduos.

\section{Decomposição do Índice de Gini}

O presente estudo utiliza a decomposiçáo do índice de Gini, descrita por Hoffmann (2006, p. 2), para identificar a participação e a contribuição de cada uma das fontes de rendimento na variaçáo da desigualdade. O índice de Gini da distribuição de renda per capita pode ser dividido em $k$ componentes, correspondentes às $k$ parcelas do rendimento total per capita dos domicílios. Assim, a decomposição do índice de Gini, no período $t\left(G_{t}\right)$, pode ser representada, de forma geral, como:

$$
G_{t}=\sum_{i=1}^{k} \varphi_{i t} C_{i t}
$$

em que: $i=1, \ldots, k$

$$
t=2001,2004,2008,2012,2015 ;
$$

$\varphi_{i t}$ : participação da parcela $i$ de rendimento, no rendimento total no período $t$, ou seja, $\varphi_{i t}=\frac{R_{i t}}{R_{t}}$; sendo $R_{i t}$ o rendimento decorrente da parcela $i$ no período $t$, e $R_{t}$ o rendimento total da população no período $t$; 
$C_{i:}$ : razão de concentração da parcela de rendimento $i$ em relação à renda total em $t$.

A razão de concentraçấo, $C_{i t}$, pode ser encontrada através da curva de Lorenz de cada um dos componentes $i$ do rendimento total dos indivíduos, sendo:

$$
C_{i t}=1-2 \beta_{i t}
$$

em que: $\beta_{i t}$ constitui a área abaixo da curva de concentraçáo da parcela de rendimento $i$, no período t. Como descrito anteriormente, essa curva mostra como a proporção acumulada da renda varia em funçáo da proporçấo acumulada da população, ordenada de acordo com o rendimento domiciliar per capita. De forma análoga, para cada um dos componentes $i$ do rendimento total, a razáo de concentração $C_{i t}$ vai representar a intensidade com que essa fonte de renda é desigual entre os indivíduos.

Através de $\varphi_{i}$, será possível observar como a composição do rendimento dos indivíduos tem se alterado ao longo dos anos; ou seja, quais fontes de renda se tornaram mais ou menos presentes no rendimento total. Ainda, através de $C_{i t}$, será possível perceber se a distribuição das parcelas do rendimento total se tornou mais ou menos desigual, ao longo dos anos. Porém, o mais interessante é verificar qual foi a contribuição da $i$-ésima parcela do rendimento, para a variação do Gini entre os períodos. Isto é, verificar, para cada um dos $i$ componentes da renda total, a seguinte variaçấo:

$$
(\Delta G)_{i t}=\left(\bar{C}_{i t}-\bar{G}_{t}\right) \Delta \varphi_{i t}+\bar{\varphi}_{i t} \Delta C_{i t},
$$

em que $(\Delta G)_{i t}$ constitui a contribuição total da parcela $i$ do rendimento, para a variação do índice de Gini do período. Mais detalhes podem ser encontrados em Soares (2006).

A contribuiçấo percentual da parcela $i$ do rendimento para a variação do Gini do período é dada por

$$
s_{i t}=\frac{100}{\Delta G_{t}}(\Delta G)_{i t}
$$

Também apresentamos a decomposição da variação do índice de Gini, conforme proposto por Hoffman
(2006). O lado direito da equaçẫo (2) possui dois componentes. O termo $\left(\bar{C}_{i t}-\bar{G}_{t}\right) \Delta \varphi_{i t}$ representa o efeito composição da fonte de renda $i$ como porcentagem da mudança no índice de Gini. O efeito composiçẫo total é dado por:

$$
\sum_{i}\left(\bar{C}_{i t}-\bar{G}_{t}\right) \Delta \varphi_{i t}
$$

Ele pode ser interpretado como o componente da variação do índice de Gini, devido às mudanças na composição da renda domiciliar total por fonte de renda. Por outro lado, o termo $\bar{\varphi}_{i t} \Delta C_{i t}$ representa o efeito concentração da fonte $i$ da renda; ou seja, a parcela da variaçáo do índice de Gini devida à variaçáo na concentração da mesma fonte de renda. De forma análoga ao efeito composição, o efeito concentração total é dado por:

$$
\sum_{i} \bar{\phi}_{i t} \Delta C_{i t}
$$

\section{Base de Dados}

As informaçóes de renda dos indivíduos estão contidas nas Pesquisas Nacionais por Amostra de Domicílios (PNAD), realizadas anualmente pelo IBGE (Instituto Brasileiro de Geografia e Estatística), constituindo a base de dados utilizada no presente estudo. Para fazer uma análise mais abrangente, utilizaremos as PNAD de 2001 (antes da criação do Bolsa Família) e também as PNADs, de 2004, 2008, 2012 e 2015. Assim como em Hoffman (2006), foi excluída a área rural da antiga regiáo Norte para as PNADs, a partir de 2004, uma vez que tal área náo estava incluída na PNAD de 2001, tornando correta a comparaçáo entre os períodos para os estados da regiáo Norte e para o Brasil como um todo. Por ser um país de proporçóes continentais e com muita heterogeneidade, será feita a avaliaçáo por unidade federativa, de forma a observar como os efeitos dos programas diferem nestas localidades, haja vista os níveis de desigualdade distintos para cada uma delas.

Para capturar os efeitos das transferências de renda sobre a desigualdade, é necessário obter todas as fontes de rendimento dos indivíduos analisados, 
para comparar o efeito que cada uma dessas rendas tem sobre a evolução da desigualdade. Seguindo a desagregação de dados descrita por Hoffmann (2006), esse rendimento total será dividido em seis parcelas, sendo elas: o rendimento de todos os trabalhos, chamado de "TRAB"; aposentadorias e pensóes oficiais, "APOG"; outras aposentadorias e pensóes, "APOO"; rendimentos de doações feitas por pessoas de outros domicílios, "DOA"; rendimentos de aluguel, "ALUG"; e o valor correspondente a outras fontes de renda, "PROG".

O rendimento de todos os trabalhos envolve o rendimento monetário dos indivíduos, obtido pelo trabalho principal, trabalhos secundários e qualquer outro trabalho realizado. As aposentadorias e pensóes oficiais envolvem aquelas fornecidas pelo governo ou por institutos de previdência, e por isso são colocadas em um grupo separado, já que sofrem a influência das medidas tomadas pelo governo. Os outros rendimentos de aposentadorias e pensóes envolvem as demais fontes desse tipo de renda, como as aposentadorias complementares. A categoria PROG envolve rendimentos com juros, dividendos, programas sociais promovidos pelo governo e outras rendas. Esse último grupo é o de grande interesse do estudo, pois ele contém a porçáo do rendimento dos indivíduos referente a transferências de renda. ${ }^{2}$ Como é possível observar, o rendimento decorrente de programas de transferência promovidos pelo governo não é obtido de forma isolada, mas em conjunto com outros tipos de rendimento, como juros e dividendos, e isso representa uma restrição dos dados. Entretanto, Hoffmann (2006) afirma que, ao que tudo indica, os indivíduos mais pobres não recebem juros e dividendos, de modo que um aumento da parcela devida de juros e dividendos levaria a um aumento da desigualdade. Nesse caso, se ainda assim captarmos um papel de redução da desigualdade da categoria PROG, é possível que estejamos subestimando o efeito redistributivo das transferências de renda.

A Tabela 1 mostra a evolução do valor total das transferências federais pelo $\mathrm{PBF}$ e pelo BPC, além dos percentuais de famílias beneficiadas pelo $\mathrm{PBF}$ e de pessoas beneficiadas pelo BPC. A soma das transferências desses dois programas representa cerca de R\$ 18 bilhôes, em 2004. Esse valor aumenta intensamente ao longo do período analisado, e chega

Tabela 1

Benefícios Transferidos e Abrangência do PBF e do BPC

\begin{tabular}{ccccc}
\hline \multirow{2}{*}{ Ano } & Total Transferido (R\$ Bilhóes) & & $\begin{array}{c}\text { \% Famílias } \\
\text { Beneficiadas pelo } \\
\text { PBF }\end{array}$ & $\begin{array}{c}\text { \% Populaçáo } \\
\text { Beneficiada pelo } \\
\text { BPC }\end{array}$ \\
\cline { 2 - 3 } & PBF & BPC & $12,6 \%$ & $1,1 \%$ \\
\hline 2004 & 7,0 & 10,8 & $16,3 \%$ & $1,2 \%$ \\
\hline 2005 & 10,0 & 13,2 & $20,0 \%$ & $1,3 \%$ \\
\hline 2006 & 12,7 & 16,4 & $19,4 \%$ & $1,5 \%$ \\
\hline 2007 & 9,2 & 18,8 & $18,1 \%$ & $1,5 \%$ \\
\hline 2009 & 16,2 & 21,1 & $20,8 \%$ & $1,7 \%$ \\
\hline 2010 & 18,1 & 24,5 & $21,0 \%$ & $1,8 \%$ \\
\hline 2011 & 19,9 & 27,8 & $21,4 \%$ & $1,9 \%$ \\
\hline 2012 & 22,5 & 29,7 & $21,8 \%$ & $1,9 \%$ \\
\hline 2013 & 26,0 & 33,8 & $21,6 \%$ & $2,0 \%$ \\
\hline 2014 & 28,8 & 36,3 & $20,8 \%$ & $2,0 \%$ \\
\hline 2015 & 29,7 & 38,3 & $20,4 \%$ & $2,1 \%$ \\
\hline
\end{tabular}

Fonte: SAGI/Ministério da Cidadania; PNAD/IBGE; INPC/IBGE; Estimativas da População/IBGE. Elaboração própria. Nota - Os dados de benefícios e de famílias beneficiadas sáo referentes aos valores de dezembro de cada ano. Os valores dos benefícios estão a preços constantes de 2015. O percentual de famílias beneficiadas é o total de famílias beneficiadas, dividido pela estimativa de domicílios da PNAD. Apesar de a denominação ser diferente, a definição de domicílios da PNAD é mais próxima à definição de famílias do PBF. 
a R\$ 67 bilhóes, em 2015. A abrangência do PBF também aumenta, passando de cerca de $12,5 \%$ para 20\%, entre 2004 e 2015, enquanto o BPC duplica a proporção de beneficiários na população, passando de $1,1 \%$ para $2,1 \%$, no mesmo período.

A despeito de não incluirmos os demais programas de transferência de renda do governo federal, o BPC e o PBF representam a maior parte das transferências desses programas. Em 2003, o BPC e os programas Bolsa Escola, Auxílio Gás e o Bolsa Alimentação, que

\section{Figura 1}

Evoluçáo do Índice de Gini para o Brasil e Regióes

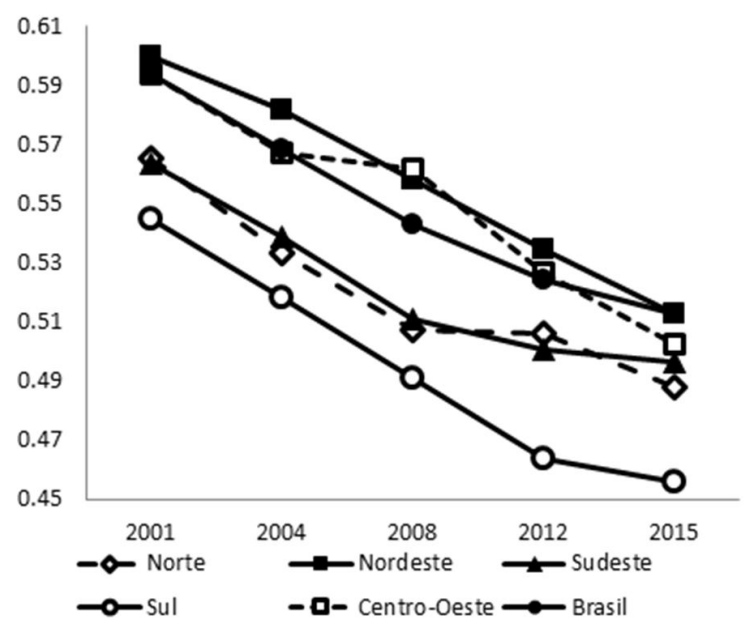

Fonte: PNAD. Elaboração própria. foram unificados no $\mathrm{PBF}$, representavam pouco mais de 70\% do valor total transferido (Cf. Brasil, 2008).

\section{Resultados}

A Figura 1 apresenta a evolução do índice de Gini para o Brasil e regióes, no período de 2001 a 2015. Percebe-se uma trajetória de queda na desigualdade de renda no país e em todas as regióes (queda de $13,6 \%$ para o Brasil, no período). A desigualdade declinou com intensidade parecida, entre 2004 e 2008 (4,5\%), e entre 2001 e 2004 (4,2\%). A redução perdeu velocidade após os primeiros quatro anos do Bolsa-Família, no período de 2008 a 2012 (3,5\%), e ainda mais no último período do estudo, entre 2012 e 2015 (2,2\%). A região Sul apresentou a maior redução na desigualdade, no período como um todo, com uma queda de $16,3 \%$, seguida das regióes Centro-Oeste e Nordeste, com quedas de $15,3 \%$ e $14,5 \%$, respectivamente. Por outro lado, a região com menor queda no período foi a região Sudeste $(11,9 \%)$, seguida da região Norte $(13,7 \%)$.

De 2001 a 2015, quase todos os estados apresentaram redução da desigualdade, exceto o Amapá, que teve leve aumento no índice de Gini, para $0,482(0,8 \%)$. Os estados da região Sul permaneceram os menos desiguais, enquanto os da regiâo Nordeste mantiveram-se como os mais desiguais. A Figura 2 coloca esses valores em mapas, separando os estados por grupos definidos pelos quartis do índice de Gini

Figura 2

Estados Brasileiros Classificados por Quartis do Índice de Gini, em 2001 e 2015
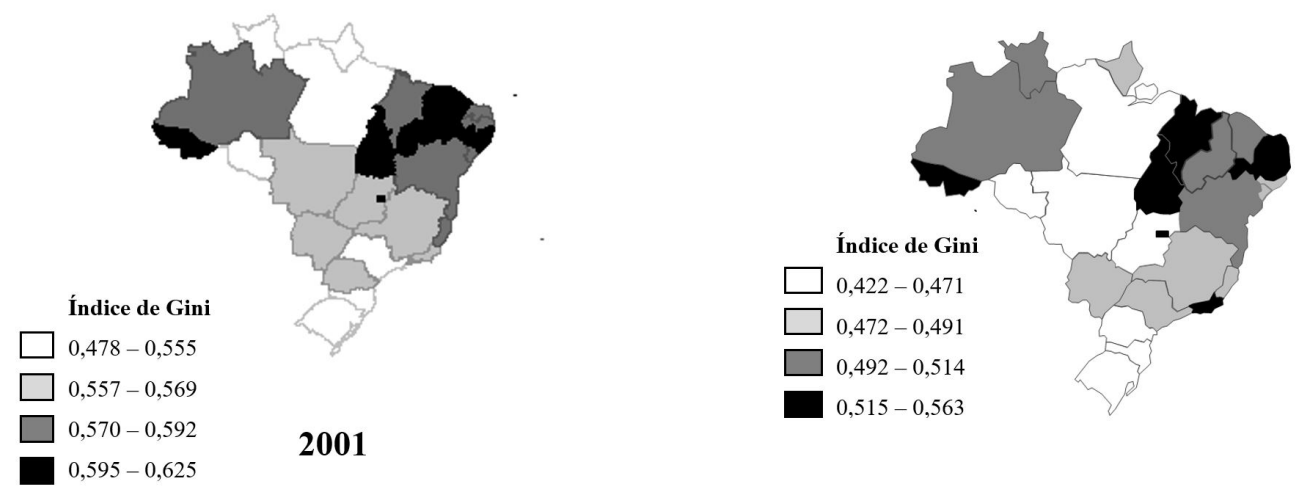

2015

Fonte: PNAD. Elaboração própria. 
Tabela 2

Renda Domiciliar per Capita e Variaçóes entre Anos

\begin{tabular}{|c|c|c|c|c|c|c|c|c|c|c|}
\hline & 2001 & 2004 & 2008 & 2012 & 2015 & $\begin{array}{c}\Delta 2004- \\
2001 \\
\text { (\% a.a.) }\end{array}$ & $\begin{array}{c}\Delta 2008- \\
2004 \\
(\% \text { a.a. })\end{array}$ & $\begin{array}{c}\Delta 2012- \\
2008 \\
(\% \text { a.a. })\end{array}$ & $\begin{array}{c}\Delta 2015- \\
2012 \\
\text { (\% a.a.) }\end{array}$ & $\begin{array}{c}\Delta 2015- \\
2012 \\
(\% \text { a.a. })\end{array}$ \\
\hline Norte & 535 & 541 & 668 & 799 & 780 & $0,4 \%$ & $5,4 \%$ & $4,6 \%$ & $-0,8 \%$ & $2,7 \%$ \\
\hline Nordeste & 396 & 416 & 546 & 668 & 665 & $1,6 \%$ & $7,0 \%$ & $5,2 \%$ & $-0,1 \%$ & $3,8 \%$ \\
\hline Sudeste & 927 & 889 & 1.092 & 1.281 & 1.260 & $-1,4 \%$ & $5,3 \%$ & $4,1 \%$ & $-0,5 \%$ & $2,2 \%$ \\
\hline Sul & 855 & 906 & 1.099 & 1.277 & 1.311 & $1,9 \%$ & $5,0 \%$ & $3,8 \%$ & $0,9 \%$ & $3,1 \%$ \\
\hline Centro-Oeste & 800 & 836 & 1.094 & 1.312 & 1.288 & $1,5 \%$ & $6,9 \%$ & $4,7 \%$ & $-0,6 \%$ & $3,5 \%$ \\
\hline Brasil & 731 & 730 & 909 & 1.074 & 1.068 & $0,0 \%$ & $5,6 \%$ & $4,3 \%$ & $-0,2 \%$ & $2,7 \%$ \\
\hline
\end{tabular}

Fonte: PNAD. Elaboração própria. Obs.: valores a preços de 2015.

de cada ano. É possível perceber a heterogeneidade entre os estados do país, ainda que, de forma geral, os valores para o índice de Gini, em 2015, sejam menores, indicando uma melhoria na distribuição de renda no país.

A Tabela 2 mostra que, entre 2001 e 2015, a renda de todas as regióes aumentou. ${ }^{3}$ Esse aumento ocorreu de forma mais acentuada na região Nordeste, o que pode ter favorecido a redução da desigualdade regional do Brasil. No período entre 2001 a 2004, houve contração da renda na região Sudeste, o que gerou estabilidade da renda do país como um todo. Já de 2012 a 2015, houve contração da renda em todas as regiōes, exceto na região Sul. É interessante notar que a renda média da região Sudeste foi ultrapassada pela renda das regióes Sul e Centro-Oeste, nesse subperíodo.

A Tabela 3 apresenta a participação de cada uma das fontes de renda na renda total dos indivíduos, bem como a sua evolução ao longo dos anos. A renda decorrente do trabalho dos indivíduos se mostra cada vez menos relevante em relação à renda total de 2001 a 2015, para todas as regióes. Ainda assim, essa fonte de renda representava mais do que $70 \%$ da renda dos indivíduos em todas as regióes e, mesmo com o início dos programas de transferência de renda, ela continuou sendo a fonte de renda mais relevante.

Em relação às aposentadorias, no período de 2001 a 2015, houve, em todas as regióes, forte aumento da relevância das aposentadorias financiadas pelo governo na renda dos indivíduos. Por outro lado, esse efeito foi contrário para as aposentadorias de outras fontes, que, de forma geral, reduziram a sua participação na renda total dos indivíduos, no período de 2001 a
Figura 3

\section{Evoluçáo da Participação da Fonte de Renda "PROG" por Regióes}

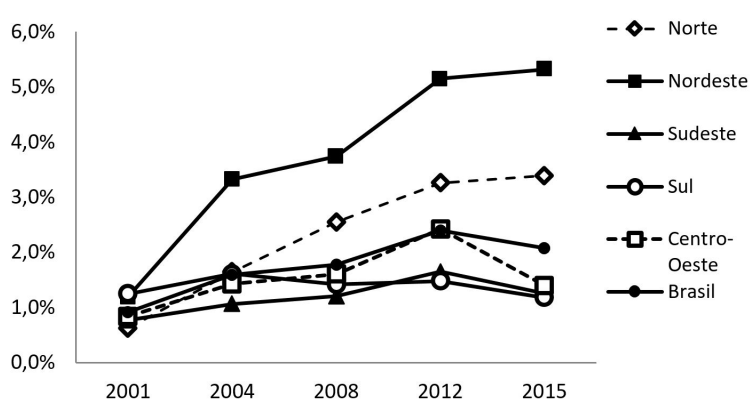

Fonte: PNAD. Elaboração própria.

2015. Tanto a participação das rendas com aluguéis, quanto a das rendas de doaçóes de terceiros, reduziram, de 2001 a 2015. Essa tendência, generalizada para todas as regióes, mostra que essas fontes de renda podem estar sendo substituídas por outras, como as aposentadorias financiadas pelo governo e a renda decorrente de programas de transferência do governo.

A Figura 3 mostra que a participação dos juros e programas de transferência do governo - foco do presente estudo -, na renda total dos indivíduos, aumentou em todas as regióes, em todos os anos, exceto na regiāo Sul, no período como um todo. As regióes Norte e Nordeste tiveram aumentos importantes da participação dessa fonte de renda na renda total, de 2,763 e 4,128 pontos percentuais, respectivamente. Apenas na região Sul, houve redução de sua participação no período total. Além disso, entre 2012 e 2015, a participação dessa fonte de renda também diminuiu nas regióes Sul, Centro-Oeste e Sudeste. 
Avaliando a distribuição dos recursos do governo destinados a programas de transferência entre as diferentes regióes do país, na Figura 4, vemos que houve uma queda de 13 e de 17 pontos percentuais, nas regióes Sul e Sudeste, respectivamente, e um aumento de 26 e 6 pontos percentuais, para as regióes Nordeste e Norte, respectivamente.

Tabela 3

Participação das Fontes de Renda na Renda Total e Variaçóes entre Anos

\begin{tabular}{|c|c|c|c|c|c|c|c|c|c|c|c|}
\hline & & 2001 & 2004 & 2008 & 2012 & 2015 & $\begin{array}{c}\Delta 01-04 \\
\text { (p.p.) }\end{array}$ & $\begin{array}{c}\Delta 04-08 \\
\text { (р.p.) }\end{array}$ & $\begin{array}{c}\Delta 08-12 \\
\text { (p.p.) }\end{array}$ & $\begin{array}{c}\Delta 12-15 \\
\text { (p.p.) }\end{array}$ & $\begin{array}{c}\Delta 01-15 \\
\text { (p.p.) }\end{array}$ \\
\hline \multirow{6}{*}{ TRAB } & Norte & $84,1 \%$ & $82,9 \%$ & $82,4 \%$ & $82,0 \%$ & $79,8 \%$ & $-1,285$ & $-0,493$ & $-0,368$ & $-2,166$ & $-4,311$ \\
\hline & Nordeste & $74,1 \%$ & $71,4 \%$ & $71,8 \%$ & $70,4 \%$ & $68,3 \%$ & $-2,641$ & 0,382 & $-1,444$ & $-2,048$ & $-5,751$ \\
\hline & Sudeste & $78,1 \%$ & $76,1 \%$ & $76,8 \%$ & $78,0 \%$ & $76,7 \%$ & $-1,970$ & 0,672 & 1,217 & $-1,331$ & $-1,412$ \\
\hline & Sul & $77,0 \%$ & $77,0 \%$ & $76,4 \%$ & $77,1 \%$ & $75,5 \%$ & 0,017 & $-0,656$ & 0,679 & $-1,514$ & $-1,474$ \\
\hline & Centro-Oeste & $83,3 \%$ & $82,7 \%$ & $81,6 \%$ & $81,9 \%$ & $80,6 \%$ & $-0,577$ & $-1,095$ & 0,237 & $-1,256$ & $-2,691$ \\
\hline & Brasil & $77,9 \%$ & $76,4 \%$ & $76,5 \%$ & $77,0 \%$ & $75,5 \%$ & $-1,562$ & 0,168 & 0,489 & $-1,516$ & $-2,420$ \\
\hline \multirow[t]{6}{*}{ APOG } & Norte & $11,9 \%$ & $11,9 \%$ & $11,8 \%$ & $12,2 \%$ & $14,2 \%$ & $-0,043$ & $-0,025$ & 0,393 & 1,951 & 2,277 \\
\hline & Nordeste & $21,0 \%$ & $21,7 \%$ & $21,2 \%$ & $21,9 \%$ & $23,7 \%$ & 0,658 & $-0,495$ & 0,668 & 1,828 & 2,659 \\
\hline & Sudeste & $17,1 \%$ & $18,9 \%$ & $18,7 \%$ & $17,7 \%$ & $19,5 \%$ & 1,729 & $-0,209$ & $-0,940$ & 1,790 & 2,370 \\
\hline & Sul & $17,3 \%$ & $17,1 \%$ & $18,2 \%$ & $18,7 \%$ & $20,4 \%$ & $-0,173$ & 1,113 & 0,488 & 1,742 & 3,170 \\
\hline & Centro-Oeste & $11,4 \%$ & $11,7 \%$ & $13,0 \%$ & $12,8 \%$ & $15,3 \%$ & 0,232 & 1,379 & $-0,190$ & 2,430 & 3,852 \\
\hline & Brasil & $17,1 \%$ & $18,1 \%$ & $18,2 \%$ & $17,9 \%$ & $19,8 \%$ & 0,982 & 0,117 & $-0,296$ & 1,852 & 2,655 \\
\hline \multirow[t]{6}{*}{ APOO } & Norte & $1,0 \%$ & $1,3 \%$ & $1,3 \%$ & $0,8 \%$ & $1,1 \%$ & 0,371 & $-0,066$ & $-0,488$ & 0,349 & 0,167 \\
\hline & Nordeste & $1,3 \%$ & $1,4 \%$ & $1,2 \%$ & $1,2 \%$ & $1,2 \%$ & 0,165 & $-0,222$ & $-0,003$ & $-0,027$ & $-0,088$ \\
\hline & Sudeste & $1,5 \%$ & $1,5 \%$ & $1,3 \%$ & $1,2 \%$ & $1,2 \%$ & 0,039 & $-0,194$ & $-0,128$ & 0,049 & $-0,234$ \\
\hline & Sul & $1,5 \%$ & $1,5 \%$ & $1,3 \%$ & $1,1 \%$ & $1,2 \%$ & $-0,034$ & $-0,176$ & $-0,267$ & 0,167 & $-0,310$ \\
\hline & Centro-Oeste & $1,6 \%$ & $1,3 \%$ & $1,3 \%$ & $1,2 \%$ & $1,0 \%$ & $-0,228$ & $-0,058$ & $-0,075$ & $-0,188$ & $-0,550$ \\
\hline & Brasil & $1,4 \%$ & $1,5 \%$ & $1,3 \%$ & $1,1 \%$ & $1,2 \%$ & 0,037 & $-0,179$ & $-0,144$ & 0,049 & $-0,237$ \\
\hline \multirow[t]{6}{*}{ ALUG } & Norte & $1,6 \%$ & $1,3 \%$ & $1,2 \%$ & $1,3 \%$ & $1,0 \%$ & $-0,297$ & $-0,036$ & 0,089 & $-0,320$ & $-0,563$ \\
\hline & Nordeste & $1,2 \%$ & $1,0 \%$ & $1,2 \%$ & $0,9 \%$ & $0,9 \%$ & $-0,215$ & 0,172 & $-0,259$ & $-0,061$ & $-0,363$ \\
\hline & Sudeste & $2,0 \%$ & $1,8 \%$ & $1,6 \%$ & $1,3 \%$ & $1,1 \%$ & $-0,190$ & $-0,186$ & $-0,341$ & $-0,209$ & $-0,926$ \\
\hline & Sul & $2,4 \%$ & $2,1 \%$ & $2,3 \%$ & $1,5 \%$ & $1,2 \%$ & $-0,240$ & 0,165 & $-0,849$ & $-0,262$ & $-1,186$ \\
\hline & Centro-Oeste & $2,1 \%$ & $2,1 \%$ & $2,1 \%$ & $1,4 \%$ & $1,3 \%$ & 0,006 & $-0,080$ & $-0,676$ & $-0,125$ & $-0,875$ \\
\hline & Brasil & $1,9 \%$ & $1,7 \%$ & $1,7 \%$ & $1,3 \%$ & $1,1 \%$ & $-0,193$ & $-0,052$ & $-0,430$ & $-0,188$ & $-0,864$ \\
\hline \multirow[t]{6}{*}{ DOA } & Norte & $0,8 \%$ & $1,0 \%$ & $0,7 \%$ & $0,4 \%$ & $0,5 \%$ & 0,234 & $-0,285$ & $-0,335$ & 0,054 & $-0,332$ \\
\hline & Nordeste & $1,2 \%$ & $1,1 \%$ & $0,8 \%$ & $0,5 \%$ & $0,6 \%$ & $-0,100$ & $-0,251$ & $-0,371$ & 0,137 & $-0,585$ \\
\hline & Sudeste & $0,6 \%$ & $0,7 \%$ & $0,4 \%$ & $0,2 \%$ & $0,3 \%$ & 0,097 & $-0,222$ & $-0,252$ & 0,098 & $-0,279$ \\
\hline & Sul & $0,5 \%$ & $0,6 \%$ & $0,4 \%$ & $0,2 \%$ & $0,4 \%$ & 0,067 & $-0,254$ & $-0,111$ & 0,168 & $-0,131$ \\
\hline & Centro-Oeste & $0,7 \%$ & $0,7 \%$ & $0,4 \%$ & $0,3 \%$ & $0,4 \%$ & $-0,023$ & $-0,318$ & $-0,116$ & 0,163 & $-0,295$ \\
\hline & Brasil & $0,7 \%$ & $0,7 \%$ & $0,5 \%$ & $0,3 \%$ & $0,4 \%$ & 0,061 & $-0,239$ & $-0,237$ & 0,121 & $-0,294$ \\
\hline \multirow[t]{6}{*}{ PROG } & Norte & $0,6 \%$ & $1,6 \%$ & $2,5 \%$ & $3,3 \%$ & $3,4 \%$ & 1,019 & 0,904 & 0,708 & 0,131 & 2,763 \\
\hline & Nordeste & $1,2 \%$ & $3,3 \%$ & $3,7 \%$ & $5,1 \%$ & $5,3 \%$ & 2,133 & 0,414 & 1,409 & 0,171 & 4,128 \\
\hline & Sudeste & $0,8 \%$ & $1,1 \%$ & $1,2 \%$ & $1,6 \%$ & $1,2 \%$ & 0,295 & 0,138 & 0,444 & $-0,397$ & 0,481 \\
\hline & Sul & $1,2 \%$ & $1,6 \%$ & $1,4 \%$ & $1,5 \%$ & $1,2 \%$ & 0,363 & $-0,192$ & 0,061 & $-0,301$ & $-0,069$ \\
\hline & Centro-Oeste & $0,8 \%$ & $1,4 \%$ & $1,6 \%$ & $2,4 \%$ & $1,4 \%$ & 0,590 & 0,172 & 0,822 & $-1,025$ & 0,559 \\
\hline & Brasil & $0,9 \%$ & $1,6 \%$ & $1,8 \%$ & $2,4 \%$ & $2,1 \%$ & 0,675 & 0,186 & 0,618 & $-0,318$ & 1,160 \\
\hline
\end{tabular}

Notas: TRAB: participação do rendimento de todos os trabalhos na renda total; APOG: participaçáo dos rendimentos com aposentadorias e pensóes oficiais na renda total; APOO: participação dos rendimentos com outras aposentadorias e pensóes na renda total; ALUG: participação dos rendimentos de aluguel na renda total; DOA: participação dos rendimentos de doações feitas por pessoas de outros domicílios na renda total e PROG: participação do valor correspondente a outras fontes de renda, incluindo programas de transferência de renda do governo na renda total. Fonte: PNAD. Elaboração própria. 
Tabela 4

Participaçáo das Regióes nos Rendimentos de Juros e Programas

\begin{tabular}{rrrr}
\hline & $\mathbf{2 0 0 1}$ & $\mathbf{2 0 0 4}$ & $\mathbf{2 0 1 5}$ \\
\hline $\mathrm{N}$ & $2,8 \%$ & $4,6 \%$ & $8,1 \%$ \\
\hline $\mathrm{NE}$ & $19,7 \%$ & $34,5 \%$ & $45,4 \%$ \\
\hline $\mathrm{SE}$ & $47,4 \%$ & $34,7 \%$ & $30,1 \%$ \\
\hline $\mathrm{S}$ & $23,1 \%$ & $18,7 \%$ & $10,1 \%$ \\
\hline Brasil & $7,0 \%$ & $7,4 \%$ & $6,4 \%$ \\
\hline
\end{tabular}

Fonte: PNAD

Tabela 5

Contribuiçáo (\%) por Fonte de Rendimento

\begin{tabular}{cccccc}
\hline & $\mathbf{( 2 0 0 1 - 2 0 0 4 )}$ & $\mathbf{( 2 0 0 4 - 2 0 0 8 )}$ & $\mathbf{( 2 0 0 8 - 2 0 1 2 )}$ & $\mathbf{( 2 0 1 2 - 2 0 1 5 )}$ & $\mathbf{( 2 0 0 1 - 2 0 1 5 )}$ \\
\hline TRAB & 67,13 & 61,52 & 34,22 & 64,89 & 57,4 \\
\hline APOG & 3,0 & 22,0 & 42,9 & $-5,0$ & 17,5 \\
\hline APOO & 3,4 & 4,1 & 1,5 & $-0,8$ & 2,5 \\
\hline ALUG & 2,5 & $-0,4$ & 5,6 & 9,6 & 3,2 \\
\hline DOA & $-1,6$ & $-0,1$ & 0,3 & 4,8 & 0,2 \\
\hline PROG & 25,6 & 13,0 & 15,5 & 26,6 & 19,2 \\
\hline
\end{tabular}

Fonte: PNAD. Elaboração própria.

Figura 4

Distribuição dos Rendimentos de Juros e Programas e Transferências do Governo

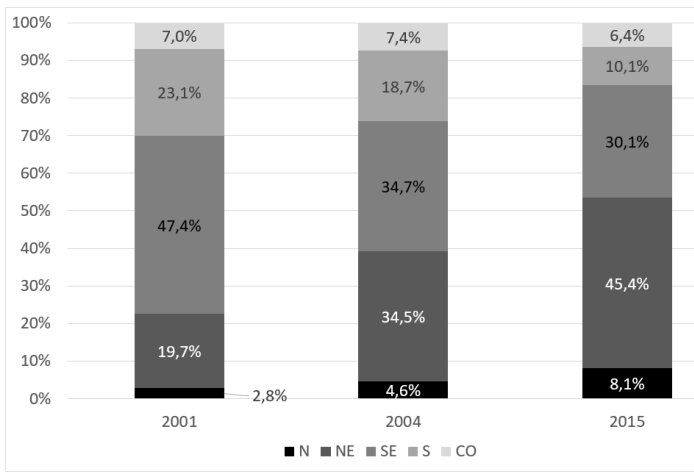

Fonte: PNAD. Elaboração própria.

As informaçóes contidas na Tabela 4 mostram que houve queda da desigualdade em todas as regióes do país. A região Sul foi a que apresentou maior redução no índice de Gini, no período de 2001 a 2015, apesar de a participação da renda proveniente dos programas de transferência na renda total dos indivíduos ter tido o menor crescimento nesse período, mantendo-se no patamar de 1,2\%. A redução de desigualdade foi menor nas regióes Norte e Nordeste, apesar dessas regióes terem apresentado a variação mais alta na dependência da renda dos indivíduos dos programas de transferência e nos recursos despendidos pelo governo com as transferências, relativamente às outras regióes. Esse resultado é diferente do esperado, já que supúnhamos que quanto maior o crescimento da participação dos programas de transferência do governo de uma região, maior seria a sua redução da desigualdade de renda. Nas próximas seçóes deste artigo, procuraremos compreender melhor essa questão.

A Tabela 5 mostra como cada fonte de renda contribuiu para aumentar ou reduzir a desigualdade de renda do país, de um período a outro. Esses valores correspondem a $s_{i t}$, conforme acima explicitado na equação (3), em que $i$ representa a fonte de renda em questão e $t$, o período. Eles medem o efeito percentual que uma parcela do rendimento total dos indivíduos teve sobre a mudança observada no índice de Gini para um determinado período; ou seja, em um contexto de redução do índice de Gini, valores positivos representam o quanto as fontes de renda contribuíram para reduzir a desigualdade. 
Para o período de 2001 a 2015, é possível perceber que a renda do trabalho, a renda com aposentadorias e pensóes do governo e a renda de programas de transferências foram as que mais contribuíram para reduzir a desigualdade de renda no país, sendo responsáveis por aproximadamente 57\%, 18\% e $19 \%$ da redução no índice de Gini, respectivamente. As parcelas de renda com outras aposentadorias e pensóes, bem como a parcela proveniente de aluguéis, tiveram um pequeno efeito positivo sobre a desigualdade, assim como as rendas de doaçóes.

As contribuiçôes de cada parcela da renda podem ser diferenciadas para cada um dos subperíodos avaliados. De 2001 a 2004, os programas de transferência de renda do governo contribuíram em 25,6\% para reduzir o índice de Gini, sendo que esse efeito pode ser resultado da primeira onda de expansão mais intensa dos programas federais de transferência de renda desde 2001, como o Bolsa Escola, Bolsa Alimentação, Auxílio Gás e PETI, que foram unificados em 2003, no Programa Bolsa Família. Já de 2004 a 2008, após os efeitos iniciais do Bolsa Família como parte da renda dos indivíduos, os efeitos dessa fonte de renda passaram a contribuir de forma mais amena para a redução do Gini, sendo responsáveis por apenas 13\% de sua redução. A partir de 2008, os programas de transferência passaram a ser mais relevantes na redução da desigualdade, contribuindo em 15,5\% da redução, de 2008 a 2012, e 26,6\%, de 2012 a 2015. Esse aumento da importância relativa dos programas de transferência de renda pode estar relacionado ao crescimento do montante transferido às famílias pelo PBF e pelo BPC (Cf. Tabela 1. Ver também Paiva, Falcão e Bartholo, 2013; Brasil, 2018).

Os resultados aqui obtidos são coerentes com aqueles de estudos anteriores da literatura, apesar de mostrarem algumas diferenças, nos períodos mais recentes. Hoffman (2009) realiza uma decomposição por fontes de renda com dados das PNADs 2001 e 2007, e encontra contribuiçóes para os rendimentos do trabalho, de aposentadorias e pensóes oficiais, e de juros e programas sociais, de respectivamente $59,8 \%, 16,2 \%$ e $19,04 \%$. As diferenças em relação aos nossos resultados mostram que, nos anos adicionais até 2012, a importância dos rendimentos do trabalho diminuiu, enquanto a relevância das aposentadorias oficiais aumentou, alinhando-se aos nossos resultados de 2008 a 2012. A partir de 2012, a importância dos rendimentos do trabalho volta a subir e a das aposentadorias oficiais volta a cair, chegando a apresentar efeito negativo sobre a redução da desigualdade.

Para investigar com mais detalhes os fatores explicativos para a redução do índice de Gini, entre 2001 e 2015, a diferença total no período pode ser decomposta entre dois efeitos por fonte de renda, de acordo com as equaçóes (2), (4) e (5). Em primeiro lugar, podemos observar, na última linha da Tabela 6 , que o efeito concentraçáo predominou e parece explicar quase que a totalidade da redução do índice de Gini, no período $(93,11 \%)$. Esse resultado indica que a queda na desigualdade de renda ocorreu devido à desconcentração de fontes relevantes de rendimento. A predominância do efeito concentração se repete nas parcelas de rendimentos do trabalho, em que responde por praticamente toda a contribuição desse fator. Isto significa que houve aumento dos salários na base da distribuição. O aumento do valor real do salário mínimo pode ser uma explicação para tal efeito. Vale a pena ressaltar, também, a predominância do efeito concentração, no caso das aposentadorias oficiais, que responderam por quase $18 \%$ da redução da desigualdade no período. Também aqui, o grande aumento do valor real do salário mínimo, que serve de referência para o valor das aposentadorias, parece explicar o fato.

No caso dos rendimentos de juros e programas sociais, os dois tipos de efeitos atuaram no sentido

\section{Tabela 6}

Decomposição da Diferença do Índice de Gini

\begin{tabular}{cccc}
\hline & \multicolumn{3}{c}{$\mathbf{2 0 0 1 - 2 0 1 5}$} \\
\cline { 2 - 4 } & $\begin{array}{c}\text { Efeito } \\
\text { Composiçăo }\end{array}$ & $\begin{array}{c}\text { Efeito } \\
\text { Concentração }\end{array}$ & Total \\
\hline TRAB & 0,17 & 57,26 & 57,43 \\
\hline APOG & $-0,24$ & 17,70 & 17,46 \\
\hline APOO & $-0,02$ & 2,55 & 2,53 \\
\hline ALUG & 2,35 & 0,86 & 3,20 \\
\hline DOA & $-0,84$ & 1,05 & 0,20 \\
\hline PROG & 5,47 & 13,70 & 19,17 \\
\hline Total & 6,89 & 93,11 & 100,00 \\
\hline
\end{tabular}

Fonte: PNAD. Elaboração própria. 
de reduzir a desigualdade. $\mathrm{O}$ efeito composição foi relevante (de cerca de um quarto da contribuição dessa fonte de renda) e é explicado pelo aumento da participação dessa fonte de renda no período, com o aumento dos recursos e da abrangência dos programas sociais do governo. $\mathrm{O}$ efeito concentração possui participação relevante e pode ser explicado pela expansão dos programas de transferências, que são altamente focalizados.

A Tabela 7 mostra os efeitos percentuais, que os rendimentos relativos a programas de transferência do governo tiveram sobre o índice de Gini, para os diferentes períodos e estados brasileiros. Entre parênteses, apresentamos as variaçóes percentuais dos índices de Gini, por estado. Por exemplo, no estado de Rondônia entre 2001 e 2004 os rendimentos de juros, programas e transferências do governo tiveram uma contribuição de $14,7 \%$ sobre a redução do índice de Gini de 0,031 . Vale notar, em primeiro lugar, que a desigualdade declinou em todos os estados brasileiros, com exceção do Amapá. Os estados com maior queda de desigualdade foram: Acre, Ceará, Pernambuco, Alagoas, Espírito Santo, Mato Grosso, Mato Grosso do Sul e Goiás. A análise da Tabela 7 permite também concluir que, em todos os estados, houve um efeito positivo dos programas de transferência de renda

Tabela 7

Contribuição (\%) dos Rendimentos de Programas e Transferências do Governo, Juros e Dividendos

\begin{tabular}{|c|c|c|c|c|c|c|c|c|c|c|c|}
\hline \multirow{2}{*}{ Regiáo } & \multirow{2}{*}{ UF } & \multicolumn{2}{|c|}{ 2001-2004 } & \multicolumn{2}{|c|}{ 2004-2008 } & \multicolumn{2}{|c|}{ 2008-2012 } & \multicolumn{2}{|c|}{ 2012-2015 } & \multicolumn{2}{|c|}{ 2001-2015 } \\
\hline & & $\Delta \mathrm{G}$ & $\Delta$ Gini & $\Delta \mathrm{G}$ & $\Delta$ Gini & $\Delta \mathrm{G}$ & $\Delta$ Gini & $\Delta \mathrm{G}$ & $\Delta$ Gini & $\Delta \mathrm{G}$ & $\Delta$ Gini \\
\hline \multirow[t]{7}{*}{ Norte } & Rondônia & 14,7 & $(-0,031)$ & 31,7 & $(-0,033)$ & 28,4 & $(-0,015)$ & $-1707,5$ & $(0,000)$ & 19,5 & $(-0,079)$ \\
\hline & Acre & 34,2 & $(-0,033)$ & 0,7 & $(-0,053)$ & $-2,3$ & $(-0,013)$ & 164,2 & $(-0,099)$ & 24,1 & $(-0,108)$ \\
\hline & Amazonas & 10,1 & $(-0,046)$ & 36,6 & $(-0,030)$ & 410,8 & $(-0,001)$ & $-15,8$ & $(-0,078)$ & 34,2 & $(-0,068)$ \\
\hline & Roraima & $-99,4$ & $(0,017)$ & 7,9 & $(-0,055)$ & $-29,6$ & $(0,019)$ & $-49,7$ & $(-0,020)$ & 50,4 & $(-0,036)$ \\
\hline & Pará & 25,9 & $(-0,035)$ & 44,2 & $(-0,012)$ & 103,1 & $(-0,005)$ & 7,7 & $(-0,053)$ & 24,7 & $(-0,092)$ \\
\hline & Amapá & $-20,2$ & $(0,054)$ & 11,4 & $(-0,084)$ & $-6,7$ & $(0,090)$ & $-3,4$ & $(0,061)$ & $-610,2$ & $(0,004)$ \\
\hline & Tocantins & 23,5 & $(-0,037)$ & 15,1 & $(-0,013)$ & 18,8 & $(-0,026)$ & 10,7 & $(-0,077)$ & 19,4 & $(-0,085)$ \\
\hline \multirow[t]{9}{*}{ Nordeste } & Maranhão & $-43,1$ & $(0,034)$ & 15,6 & $(-0,081)$ & $-67,8$ & $(0,025)$ & $-8,9$ & $(-0,022)$ & 123,1 & $(-0,035)$ \\
\hline & Piauí & 158,1 & $(-0,010)$ & 24,8 & $(-0,016)$ & 27,0 & $(-0,026)$ & 6,9 & $(-0,052)$ & 32,2 & $(-0,084)$ \\
\hline & Ceará & 35,0 & $(-0,036)$ & 15,0 & $(-0,032)$ & 84,1 & $(-0,017)$ & 2,0 & $(-0,085)$ & 27,3 & $(-0,117)$ \\
\hline & $\begin{array}{l}\text { Rio Grande do } \\
\text { Norte }\end{array}$ & 142,9 & $(-0,011)$ & $-7,1$ & $(-0,020)$ & 31,7 & $(-0,020)$ & 17,3 & $(-0,052)$ & 33,1 & $(-0,076)$ \\
\hline & Paraíba & $-590,5$ & $(0,002)$ & $-5,2$ & $(-0,012)$ & 18,4 & $(-0,055)$ & $-21,8$ & $(-0,065)$ & 27,3 & $(-0,069)$ \\
\hline & Pernambuco & 145,4 & $(-0,010)$ & 15,1 & $(-0,041)$ & 7,9 & $(-0,058)$ & 4,3 & $(-0,109)$ & 25,4 & $(-0,095)$ \\
\hline & Alagoas & 28,4 & $(-0,044)$ & $-263,6$ & $(0,005)$ & 17,8 & $(-0,081)$ & $-5,2$ & $(-0,120)$ & 27,8 & $(-0,137)$ \\
\hline & Sergipe & 62,9 & $(-0,011)$ & 21,8 & $(-0,024)$ & $-251,9$ & $(0,004)$ & 8,5 & $(-0,030)$ & 29,7 & $(-0,090)$ \\
\hline & Bahia & 32,8 & $(-0,037)$ & $-173,0$ & $(0,004)$ & 60,1 & $(-0,013)$ & 8,7 & $(-0,045)$ & 35,8 & $(-0,082)$ \\
\hline \multirow[t]{4}{*}{ Sudeste } & Minas Gerais & 33,2 & $(-0,017)$ & 5,0 & $(-0,029)$ & 16,4 & $(-0,016)$ & 60,1 & $(-0,062)$ & 18,6 & $(-0,066)$ \\
\hline & Espírito Santo & 14,5 & $(-0,042)$ & 3,0 & $(-0,032)$ & $-1,4$ & $(-0,022)$ & 28,3 & $(-0,096)$ & 8,1 & $(-0,101)$ \\
\hline & Rio de Janeiro & 11,8 & $(-0,021)$ & 37,3 & $(-0,009)$ & 39,0 & $(-0,009)$ & $-86,7$ & $(-0,039)$ & 25,8 & $(-0,039)$ \\
\hline & São Paulo & 10,1 & $(-0,025)$ & 4,8 & $(-0,030)$ & $-43,5$ & $(-0,004)$ & 87,8 & $(-0,059)$ & 12,0 & $(-0,066)$ \\
\hline \multirow[t]{3}{*}{ Sul } & Paraná & 10,0 & $(-0,020)$ & 11,3 & $(-0,047)$ & 3,8 & $(-0,018)$ & 20,7 & $(-0,085)$ & 10,4 & $(-0,096)$ \\
\hline & Santa Catarina & 5,3 & $(-0,037)$ & $-3,8$ & $(0,006)$ & 5,0 & $(-0,043)$ & $-18,6$ & $(-0,075)$ & 5,9 & $(-0,073)$ \\
\hline & Rio Grande do Sul & 18,9 & $(-0,027)$ & 12,0 & $(-0,023)$ & 2,8 & $(-0,028)$ & 16,3 & $(-0,078)$ & 11,6 & $(-0,088)$ \\
\hline \multirow[t]{4}{*}{$\begin{array}{l}\text { Centro- } \\
\text { Oeste }\end{array}$} & $\begin{array}{l}\text { Mato Grosso do } \\
\text { Sul }\end{array}$ & 23,8 & $(-0,038)$ & 67,8 & $(-0,005)$ & 6,7 & $(-0,039)$ & 43,8 & $(-0,082)$ & 21,2 & $(-0,093)$ \\
\hline & Mato Grosso & 6,4 & $(-0,044)$ & $-22,1$ & $(0,017)$ & $-75,7$ & $(-0,023)$ & 33,6 & $(-0,050)$ & 8,4 & $(-0,119)$ \\
\hline & Goiás & 32,9 & $(-0,031)$ & $-4,3$ & $(-0,025)$ & 1,8 & $(-0,030)$ & 8,6 & $(-0,087)$ & 9,9 & $(-0,117)$ \\
\hline & Distrito Federal & $-255,7$ & $(0,002)$ & $-11,5$ & $(-0,003)$ & $-2,0$ & $(-0,035)$ & 0,6 & $(-0,036)$ & 6,8 & $(-0,054)$ \\
\hline Brasil & & 25,6 & $(-0,025)$ & 13,0 & $(-0,026)$ & 15,5 & $(-0,019)$ & 26,6 & $(-0,069)$ & 19,2 & $(-0,081)$ \\
\hline
\end{tabular}


sobre a desigualdade, no período como um todo. Apesar de apresentar sinal negativo na contribuição dos outros rendimentos, o estado do Amapá teve um aumento da desigualdade no período, de modo que essa fonte de renda também contribuiu no sentido de reduzi-la. Nas regióes Norte e Nordeste, é possível observar os valores mais elevados no efeito dos programas de transferência sobre a desigualdade, ao passo que os estados das regióes Sul e Sudeste apresentaram valores mais baixos. Tal resultado se alinha ao maior crescimento da participação do rendimento de programas de transferência do governo, no rendimento total nas regióes Norte e Nordeste, e menor crescimento, nas regiōes Sul e Sudeste. Vale

Tabela 8

Contribuição (\%) e Parcelas da Variação do Índice de Gini devido às Fontes de Renda

\begin{tabular}{|c|c|c|c|c|c|c|c|c|c|c|c|}
\hline \multirow{2}{*}{ Norte } & \multirow[b]{2}{*}{ Trabalho } & \multicolumn{2}{|c|}{ 2001-2004 } & \multicolumn{2}{|c|}{ 2004-2008 } & \multicolumn{2}{|c|}{ 2008-2012 } & \multicolumn{2}{|c|}{ 2012-2015 } & \multicolumn{2}{|c|}{ 2001-2015 } \\
\hline & & 73,6 & $(-0.024)$ & 60,6 & $(-0.015)$ & $-422,1$ & $(0.007)$ & 64,3 & $(-0.012)$ & 56,0 & $(-0.044)$ \\
\hline & Apos. Gov. & 1,9 & $(-0.001)$ & 10,0 & $(-0.003)$ & 193,7 & $(-0.003)$ & 7,9 & $(-0.001)$ & 10,9 & $(-0.008)$ \\
\hline & Apos. Out. & $-0,5$ & $(0.000)$ & 1,8 & $(0.000)$ & 34,7 & $(-0.001)$ & 3,7 & $(-0.001)$ & 1,9 & $(-0.001)$ \\
\hline & Aluguéis & 3,0 & $(-0.001)$ & 0,2 & $(0.000)$ & 4,0 & $(0.000)$ & 6,3 & $(-0.001)$ & 2,8 & $(-0.002)$ \\
\hline & Doaçôes & $-2,4$ & $(0.001)$ & 1,2 & $(0.000)$ & $-13,1$ & $(0.000)$ & 8,0 & $(-0.001)$ & 0,8 & $(-0.001)$ \\
\hline & Programas e out. & 24,3 & $(-0.008)$ & 26,2 & $(-0.007)$ & 302,8 & $(-0.005)$ & 9,7 & $(-0.002)$ & 27,5 & $(-0.021)$ \\
\hline & Total & 100,0 & $(-0.033)$ & 100,0 & $(-0.026)$ & 100,0 & $(-0.002)$ & 100,0 & $(-0.018)$ & 100,0 & $(-0.078)$ \\
\hline \multirow[t]{7}{*}{ Nordeste } & Trabalho & 43,3 & $(-0.008)$ & 40,1 & $(-0.009)$ & 22,3 & $(-0.005)$ & 84,2 & $(-0.018)$ & 47,1 & $(-0.041)$ \\
\hline & Apos. Gov. & $-13,9$ & $(0.003)$ & 31,6 & $(-0.007)$ & 30,5 & $(-0.007)$ & 0,6 & $(0.000)$ & 14,6 & $(-0.013)$ \\
\hline & Apos. Out. & $-1,0$ & $(0.000)$ & 6,5 & $(-0.002)$ & 2,4 & $(-0.001)$ & 2,1 & $(0.000)$ & 2,7 & $(-0.002)$ \\
\hline & Aluguéis & 4,3 & $(-0.001)$ & $-2,9$ & $(0.001)$ & 3,7 & $(-0.001)$ & 2,9 & $(-0.001)$ & 1,8 & $(-0.002)$ \\
\hline & Doações & $-4,6$ & $(0.001)$ & $-1,3$ & $(0.000)$ & $-0,2$ & $(0.000)$ & 3,9 & $(-0.001)$ & $-0,3$ & $(0.000)$ \\
\hline & Programas e out. & 72,0 & $(-0.013)$ & 26,1 & $(-0.006)$ & 41,4 & $(-0.010)$ & 6,2 & $(-0.001)$ & 34,1 & $(-0.030)$ \\
\hline & Total & 100,0 & $(-0.018)$ & 100,0 & $(-0.024)$ & 100,0 & $(-0.023)$ & 100,0 & $(-0.022)$ & 100,0 & $(-0.087)$ \\
\hline \multirow[t]{7}{*}{ Sudeste } & Trabalho & 82,7 & $(-0.021)$ & 65,1 & $(-0.018)$ & 22,1 & $(-0.002)$ & 1,1 & $(0.000)$ & 61,3 & $(-0.041)$ \\
\hline & Apos. Gov. & $-0,8$ & $(0.000)$ & 23,2 & $(-0.006)$ & 66,3 & $(-0.007)$ & $-13,5$ & $(0.001)$ & 18,2 & $(-0.012)$ \\
\hline & Apos. Out. & 3,5 & $(-0.001)$ & 3,9 & $(-0.001)$ & 1,0 & $(0.000)$ & $-9,7$ & $(0.000)$ & 2,3 & $(-0.002)$ \\
\hline & Aluguéis & 1,7 & $(0.000)$ & 1,3 & $(0.000)$ & 6,0 & $(-0.001)$ & 20,2 & $(-0.001)$ & 3,3 & $(-0.002)$ \\
\hline & Doaçóes & $-0,8$ & $(0.000)$ & $-0,8$ & $(0.000)$ & 2,2 & $(0.000)$ & 14,5 & $(-0.001)$ & 0,6 & $(0.000)$ \\
\hline & Programas e out. & 13,7 & $(-0.003)$ & 7,1 & $(-0.002)$ & 2,4 & $(0.000)$ & 87,4 & $(-0.004)$ & 14,3 & $(-0.010)$ \\
\hline & Total & 100,0 & $(-0.025)$ & 100,0 & $(-0.027)$ & 100,0 & $(-0.010)$ & 100,0 & $(-0.005)$ & 100,0 & $(-0.067)$ \\
\hline \multirow[t]{7}{*}{ Sul } & Trabalho & 61,0 & $(-0.016)$ & 61,0 & $(-0.016)$ & 51,2 & $(-0.014)$ & 80,0 & $(-0.007)$ & 59,3 & $(-0.053)$ \\
\hline & Apos. Gov. & 18,8 & $(-0.005)$ & 24,9 & $(-0.007)$ & 34,8 & $(-0.009)$ & $-16,5$ & $(0.001)$ & 23,2 & $(-0.021)$ \\
\hline & Apos. Out. & 5,6 & $(-0.002)$ & 5,5 & $(-0.001)$ & 0,2 & $(0.000)$ & $-10,4$ & $(0.001)$ & 2,5 & $(-0.002)$ \\
\hline & Aluguéis & 4,0 & $(-0.001)$ & $-4,4$ & $(0.001)$ & 8,8 & $(-0.002)$ & 27,1 & $(-0.002)$ & 4,8 & $(-0.004)$ \\
\hline & Doaçôes & $-1,5$ & $(0.000)$ & 1,2 & $(0.000)$ & 1,0 & $(0.000)$ & 0,8 & $(0.000)$ & 0,3 & $(0.000)$ \\
\hline & Programas e out. & 12,1 & $(-0.003)$ & 11,8 & $(-0.003)$ & 3,9 & $(-0.001)$ & 18,9 & $(-0.002)$ & 9,9 & $(-0.009)$ \\
\hline & Total & 100,0 & $(-0.027)$ & 100,0 & $(-0.027)$ & 100,0 & $(-0.027)$ & 100,0 & $(-0.008)$ & 100,0 & $(-0.089)$ \\
\hline \multirow{7}{*}{$\begin{array}{l}\text { Centro- } \\
\text { Oeste }\end{array}$} & Trabalho & 60,2 & $(-0.016)$ & 109,5 & $(-0.006)$ & 75,2 & $(-0.027)$ & 76,8 & $(-0.018)$ & 73,1 & $(-0.066)$ \\
\hline & Apos. Gov. & 5,9 & $(-0.002)$ & $-18,0$ & $(0.001)$ & 28,4 & $(-0.010)$ & $-10,8$ & $(0.003)$ & 9,4 & $(-0.009)$ \\
\hline & Apos. Out. & 7,2 & $(-0.002)$ & 0,7 & $(0.000)$ & $-0,1$ & $(0.000)$ & 5,3 & $(-0.001)$ & 3,5 & $(-0.003)$ \\
\hline & Aluguéis & 1,2 & $(0.000)$ & $-8,3$ & $(0.000)$ & 3,2 & $(-0.001)$ & 5,5 & $(-0.001)$ & 2,5 & $(-0.002)$ \\
\hline & Doaçóes & $-2,2$ & $(0.001)$ & 8,2 & $(0.000)$ & 0,0 & $(0.000)$ & $-0,8$ & $(0.000)$ & $-0,3$ & $(0.000)$ \\
\hline & Programas e out. & 27,7 & $(-0.007)$ & 7,7 & $(0.000)$ & $-6,7$ & $(0.002)$ & 24,0 & $(-0.006)$ & 11,6 & $(-0.011)$ \\
\hline & Total & 100,0 & $(-0.027)$ & 100,0 & $(-0.005)$ & 100,0 & $(-0.035)$ & 100,0 & $(-0.024)$ & 100,0 & $(-0.091)$ \\
\hline
\end{tabular}

Fonte: PNAD. Elaboração própria. 
notar que a contribuição dos programas sociais para o declínio de renda gira em torno de $20 \%$ a $30 \%$, em quase todos os estados, e que, nos estados em que houve maior queda de desigualdade por outros motivos (renda do trabalho e aposentadorias, por exemplo), essa participação é menor.

A Tabela 8 mostra a contribuição de cada fonte de rendimento para a variação do índice de Gini por regiâo, além da parcela daquela variação dentro dos parênteses. ${ }^{4}$ Por exemplo, na regiāo Norte entre 2001 e 2004, os rendimentos do trabalho foram responsáveis por $73,6 \%$ da redução de 0.033 do índice de Gini. Os rendimentos de programas sociais, juros e dividendos foram responsáveis por $24,3 \%$ dessa redução. Em primeiro lugar, podemos constatar que, no período de 2001 a 2015, nas regiōes Norte e Nordeste, os rendimentos de juros e programas sociais tiveram contribuiçôes muito relevantes, explicando cerca de 28\% e 34\% da redução do índice de Gini, respectivamente. Nas demais regióes, os percentuais correspondentes variam próximos de $10 \%$ e $15 \%$. Adicionalmente, nos valores entre parênteses, podemos ver que as parcelas de contribuição foram, de fato, muito relevantes nas regióes Norte e Nordeste (com reduçôes de mais de 0,02 do índice de Gini), enquanto, nas demais regiôes, essa contribuição foi pequena (redução de no máximo 0,011 do índice de Gini). Por outro lado, as contribuições dos rendimentos do trabalho, no período como um todo, foram muito maiores, tanto em termos relativos (entre $47 \%$ e $73 \%$ ), quanto nas parcelas do índice de Gini (no mínimo -0,041), em todas as regióes.

Ao analisar os efeitos por subperíodos em cada região, podemos notar alguns resultados interessantes.
O rendimento do trabalho ganha proeminência para explicar a queda da desigualdade nas regiōes Norte e Nordeste, no período recessivo, enquanto os rendimentos de programas sociais têm maior poder explicativo, nos períodos de 2001 a 2004, e de 2008 a 2012. Por outro lado, na região Sudeste, ocorre o contrário: o rendimento do trabalho perde força para explicar a queda da desigualdade no período recessivo, enquanto as transferências de renda ganham poder explicativo. Nas regióes Sul e Centro-Oeste, tanto os rendimentos do trabalho, como as transferências de renda (em menor grau), contribuíram para a pequena queda da desigualdade observada nesse último período. Os efeitos da aposentadoria do governo são maiores, nos períodos de 2004 a 2008, e de 2008 a 2012, em todas as regióes, provavelmente por conta do maior aumento do salário mínimo nesse período, perdendo força no período recessivo.

Por último, a Tabela 9 mostra a decomposição das contribuiçóes da fonte de juros e programas sociais para a redução da desigualdade por regiāo. Podemos observar que, nas regióes Norte e Nordeste, onde as contribuiçốes dessa fonte de renda foram maiores, o efeito composição apresenta os maiores valores dentre as regiōes, explicando aproximadamente $50 \%$ e $74 \%$ das contribuiçóes daquela fonte de renda, respectivamente. Parte desse resultado é explicado pelo fato de que, naquelas regióes, as médias de renda per capita são as menores do Brasil, de modo que aumentos dessa fonte de recursos representam variaçôes de participação comparativamente maiores. Esse resultado é também consistente com o aumento de recursos transferidos àquelas duas regióes, conforme observado na Figura 3. Nas demais regiôes,

Tabela 9

Decomposiçáo da Contribuiçáo (\%) dos Rendimentos de Juros e Programas e Transferências do Governo

\begin{tabular}{lcccccc}
\hline \multirow{2}{*}{ UF } & \multicolumn{9}{c}{$\mathbf{2 0 0 1 - 2 0 1 5}$} \\
\cline { 2 - 7 } & \multicolumn{2}{c}{ Ef. Composiçáo } & \multicolumn{2}{c}{ Ef. Concentraçáo } & \multicolumn{2}{c}{ Total } \\
\hline Norte & 13,3 & $(48 \%)$ & 14,3 & $(52 \%)$ & 27,5 & $(100 \%)$ \\
\hline Nordeste & 25,2 & $(74 \%)$ & 8,8 & $(26 \%)$ & 34,1 & $(100 \%)$ \\
\hline Sudeste & 1,8 & $(13 \%)$ & 12,5 & $(87 \%)$ & 14,3 & $(100 \%)$ \\
\hline Sul & $-0,2$ & $(-2 \%)$ & 10,1 & $(102 \%)$ & 9,9 & $(100 \%)$ \\
\hline Centro-Oeste & 2,2 & $(19 \%)$ & 9,5 & $(81 \%)$ & 11,6 & $(100 \%)$ \\
\hline Brasil & 5,5 & $(29 \%)$ & 13,7 & $(71 \%)$ & 19,2 & $(100 \%)$ \\
\hline
\end{tabular}


predomina o efeito concentração, pelo fato de que elas são relativamente mais ricas e os programas de transferência são focalizados.

Em resumo, apesar dos efeitos particulares de cada estado e região brasileiros, é possível afirmar que, no país, de forma geral, e em todos os períodos, os programas de transferência do governo tiveram efeitos no sentido de reduzir a desigualdade. Mesmo com a constatação anterior, de que regióes com maior crescimento da participação da renda de programas de transferência na renda total tiveram as menores reduçóes no índice de Gini, o efeito total dos rendimentos com programas sobre o índice de Gini foi positivo, de 2001 a 2015, mostrando que eles contribuíram para a redução da desigualdade de renda no país.

\section{Consideraçóes finais}

Desde 2001, a desigualdade de renda no Brasil tem diminuído. O índice de Gini da renda domiciliar per capita reduziu em 13,6\%, de 2001 a 2015, sendo que a queda mais intensa ocorreu de 2004 a 2008 (4,5\%), logo após a unificação dos programas federais de transferência de renda no Programa Bolsa-Família, em 2003. Com ele, os programas de transferência de renda do governo ganharam importância e atenção, como medidas relevantes para reduzir a pobreza, e tiveram efeitos no sentido de reduzir a desigualdade de renda. Dada a magnitude da desigualdade no Brasil e os impactos que ela tem sobre a economia e o desenvolvimento do país, é importante entender como as diferentes fontes de renda contribuem para a variação na desigualdade. Desta forma, é possível analisar se a redução observada no índice de Gini foi resultado dos esforços do governo em reduzi-lo através de programas sociais, ou se outros fatores foram seus reais geradores.

Apesar da vasta literatura existente sobre o assunto, especialmente no Brasil, onde os programas de transferência são tão relevantes, poucos estudos analisaram dados táo recentes e desagregados por unidade federativa. Assim, a contribuição principal do presente estudo foi de analisar dados por um período maior de tempo, de 2001 a 2015, o que permitiu examinar efeitos de programas sociais sobre a desigualdade, no curto e longo prazos, incluindo períodos de expansão e recessão da economia brasileira. Além disso, entender como o efeito dos programas sobre a desigualdade variou entre os diferentes estados é outro diferencial do estudo, dadas as claras distinções existentes entre eles.

Para identificar o impacto dos programas na evoluçáo da desigualdade no Brasil, foi coletado o rendimento domiciliar per capita, nas PNADs de 2001, 2004, 2008, 2012 e 2015, e depois segmentado em seis parcelas: rendimento de todos os trabalhos; aposentadorias e pensóes oficiais e não oficiais; doaçôes; aluguéis; e os programas sociais. Através da metodologia de decomposição do índice de Gini, foi calculado o impacto percentual que a variação em cada uma dessas fontes teve sobre a desigualdade; ou seja, como cada parcela contribuiu para a sua redução.

Com essa análise, foi possível concluir que a fonte de renda que mais contribuiu para reduzir o índice de Gini, entre 2001 e 2015, foi a proveniente de todos os trabalhos (contribuição de 57,5\%), seguida da renda dos programas sociais e juros de aplicaçóes (19\%), pouco acima da contribuição das aposentadorias $(17,5 \%)$. Nossos resultados mostram que quase toda a redução do índice de Gini (93,11\% dela) se deve à diminuição da concentração das fontes de renda, especialmente entre os rendimentos do trabalho e das aposentadorias oficiais. O efeito composição entre rendimentos de juros e programas sociais foi relevante (contribuição de 5,5\% para a redução do índice de Gini), sugerindo que, para essa fonte de renda, a expansão da abrangência dos programas e o volume de recursos transferidos teve impactos importantes.

Quebrando a análise por subperíodos, observamos que a renda proveniente de programas sociais foi a segunda mais relevante, no período de 2001 a 2004, apresentando, porém, contribuiçóes relativamente menores, nos períodos seguintes, e voltando a ocupar a segunda posição, somente no último subperíodo de análise, de 2012 a 2015, que abrange a recente recessão econômica. Este padrão sugere que a importância desta fonte de renda pode estar relacionada ao ciclo econômico e à eficácia das transferências governamentais em reduzir a desigualdade de renda. Após o período inicial de implantação, a contribuição do Bolsa Família pode ter se reduzido relativamente 
aos rendimentos do trabalho, em um período de crescimento da média salarial e do salário mínimo, e de redução da taxa de desemprego. A partir de 2012, a importância relativa dos programas sociais pode ter aumentado, devido à recessão econômica a partir do final de 2014. Por outro lado, as aposentadorias do governo apresentaram contribuições crescentes até 2012, para a redução da desigualdade, o que possui relaçáo com o crescimento real do salário mínimo, como também comprovado por Hoffman (2013). Em contrapartida, elas voltaram a apresentar efeitos menores no período de 2012 a 2015, chegando a atuar no sentido de aumentar a desigualdade no país, o que aconteceu também de 1997 a 2004, como apresentado por Hoffmann (2006).

Nossa investigação foi, também, realizada por regióes. Entre 2001 e 2015, apesar da importância dos rendimentos do mercado de trabalho em todas as regióes brasileiras, os resultados sugerem que os programas sociais exerceram um papel relativamente maior na reduçấo da desigualdade, nas regióes Norte e Nordeste. Na comparaçáo com base nas parcelas de redução do índice de Gini entre regiôes, a redução devido ao rendimento de juros e programas sociais, nas regiôes Norte e Nordeste (contribuiçōes de 27,5\% e 34\% para a redução dos índices de Gini), foi comparativamente maior nessas regiôes, do que nas demais (contribuição de no máximo 14.5\%, na redução do índice de Gini).

Em nossas decomposiçôes das contribuiçôes dos rendimentos de juros e programas sociais dentro das regiōes, verificamos que, nas regiōes Norte e Nordeste, a contribuição dos rendimentos de juros e programas sociais para a reduçáo do índice de Gini ocorreu significantemente via efeito composição, o que parece ser coerente com o aumento proporcionalmente maior dos recursos repassados pelo governo, naquelas regiōes. Em contraste, nas demais regióes, o efeito concentração foi mais relevante, devido à característica de focalização dos programas de transferência de renda.

Em uma análise ainda mais detalhada, para cada um dos estados brasileiros, foi possível observar que todos eles tiveram efeitos positivos dos programas de transferência de renda sobre a redução da desigualdade. Os resultados mostram que os rendimentos provenientes do trabalho, de aluguéis, doações e aposentadorias privadas ocupam uma porção cada vez menor do rendimento total dos indivíduos, enquanto há um crescimento da participação dos rendimentos de programas sociais e de aposentadorias do governo, no rendimento total. Além disso, o governo buscou focalizar seus recursos nas regiōes onde os programas de transferência realmente teriam um maior impacto na desigualdade, aumentando a porção dos recursos destinados às regiôes Norte e Nordeste, em comparação à porçẫo destinada às demais regiōes. Apesar desses esforços, verificamos que a variação do índice de Gini foi maior em regióes com efeitos mais importantes de outras fontes de renda, como a regiáo Sul, comparativamente às regiốes que foram mais influenciadas pelos programas, como é o caso da região Norte, que teve a menor redução do índice de Gini, de 2001 a 2015.

\section{Notas}

1 O Benefício de Prestação Continuada é um benefício individual, não vitalício e intransferível, promovido pelo governo brasileiro, e que assegura a transferência mensal de um salário mínimo a idosos com 65 anos ou mais, bem como a pessoas de qualquer idade, com deficiência, seja ela física ou intelectual. Para recebê-lo, o indivíduo deve comprovar que não possui meios de garantir o próprio sustento, tendo renda mensal familiar per capita inferior a um quarto do salário mínimo vigente.

2 Aqui, estâo compreendidos todos os rendimentos de programas de transferências de renda, como o PBF, o BPC, a Renda Mensal Vitalícia, além dos programas unificados pelo PBF na sua criação (Bolsa-Escola, Bolsa-Alimentação e Auxílio Gás).

3 Utilizamos como deflator o Índice de Preços ao Consumidor Amplo (IPCA), obtido no site do IBGE.

4 Mais precisamente, reportamos os valores estimados de $(\Delta G)_{i t}$ da equação (2).

\section{BIBLIOGRAFIA}

ARAUJO, Jair Andrade de \& MORAIS, Gabriel Alves de Sampaio (2014), "Desigualdade de renda e sua decomposiçáo no Brasil e nas regiōes 
brasileiras". Revista Econômica do Nordeste, 45 (4): 35-51, out./dez. 2014.

ARRETCHE, Marta (2018), "Democracia e redução da desigualdade econômica no Brasil: A inclusão dos outsiders". Revista Brasileira de Ciências Sociais, 33(96).

ATHANASOPOULOS, George \& VAHID, Farshid (2003), "Statistical inference and changes in income inequality in Australia". The Economic Record, 79(247): 412-424.

BALVOCIUTE, Rasa (2004), "Changes in income inequality in the EU countries in 2005-2011". Economics and Business, 25: 6-11.

BARROS, Ricardo Paes de; CARVALHO, Mirela de \& FRANCO, Samuel (2007), "O Papel das transferências públicas na queda recente da desigualdade de renda brasileira”. Desigualdade de renda no Brasil: uma análise da queda recente. Brasil: IPEA. V. 2: 42-86. 2007.

BERTONI NETO, João; SOUZA, Solange de Cassia Inforzato \& FERREIRA, Carlos Roberto (2013), "A contribuição das rendas do trabalho e dos programas de transferências de renda para a queda da desigualdade nas áreas urbana e rural no Brasil: 2004-2008”. Pesquisa \& Debate, 24 (1): $24-46$.

BRASIL. MINISTÉRIO DO DESENVOLVIMENTO SOCIAL E COMBATE À FOME. Secretaria Nacional de Assistência Social (2008). "Financiamento da Assistência Social no Brasil". Caderno SUAS, V. 3, Ano 3, 2008.

BRASIL. MINISTÉRIO DA TRANSPARÊNCIA E CONTROLADORIA-GERAL DA UNIÃO. "Avaliação dos Dados Cadastrais do Benefício de Prestação Continuada (BPC) Utilizados para a Concessão e Manutenção dos Benefícios. Exercício 2018".

BRITO, Alessandra Scalioni (2011), "Efeitos esperados pela teoria econômica de políticas de transferência de renda sobre o mercado de trabalho". Centro de Estudos sobre Desigualdade e Desenvolvimento, texto para discussão n43.

CARNEIRO, Douglas Mesquita; ALVIM, Augusto Mussi \& BAGOLIN, Izete Pengo (2012), "Programa de Transferência de renda e desigualdade: impactos do programa bolsa-família sobre a desigualdade de renda no Rio Grande do Sul de 2004 a 2009”.

CENTRAL INTELLIGENCE AGENCY: The World Factbook - Country Comparison: Distribution of Family Income - GINI Index, 2014. Disponível em: <https://www.cia.gov/library/publications/ the-world-factbook/rankorder/2172rank.html>. Acesso em: 23 set. 2014.

CODACE (2017). "Comunicado de Datação de Ciclos Mensais Brasileiros”.

DALATU, Paul Inuwa (2016), “Time Complexity of K-Means and K-Medians Clustering Algorithms in Outliers Detection”. Global Journal of Pure and Applied Mathematics, 12(5): 4405-4418.

DEDECCA, Claudio Salvadori (2014), "A queda da desigualdade de renda corrente e a participação do 1\% de domicílios de maior renda, 2000-2010". Revista de Economia Política, 34(2): 249-265. DIXON, Sylvia \& MARÉ, David Christopher (2007), "Understanding changes in Maori incomes and income inequality 1997-2003". Journal of Population Economics, 20: 571-598.

FERRAZ, Lúcio Flávio (2008), "Programa Bolsa Família: Impactos na distribuição de renda”. Monografia (Especialização em Orçamento Público), Tribunal de Contas da União. Brasília.

FERREIRA, Roberto Tatiwa \& CRUZ, Mércia Santos da (2010), "Efeitos da Educação, da Renda do Trabalho, das transferências e das condiçóes iniciais na evolução da desigualdade de renda nos municípios brasileiros no período de 1991 a 2000". Pesquisa e Planejamento Econômico, 40 (1): 103-121.

GABRIEL, Flávio Braga de Almeida; FERREIRA, Carlos Roberto \& EBERHARDT, Paulo Henrique de Cezaro (2015), "Análise do comportamento da desigualdade da renda domiciliar per capita do Paraná, 2004 - 2012”. Seminário Internacional sobre Desenvolvimento Regional, VII., 2015, Rio Grande do Sul. Disponível em: <http:// online.unisc.br/acadnet/anais/index.php/sidr/ article/view/13441>. Acesso em 26 abr. 2017.

GABRIEL, Flávio Braga de Almeida (2014), “A recente evolução da distribuição da renda na Regiāo Norte do Brasil”. 
HELFAND, Steven M.; ROCHA, Rudi \& VINHAIS, Henrique Eduardo Ferreira (2009), "Pobreza e desigualdade de renda no Brasil rural: uma análise da queda recente". Pesquisa e Planejamento Econômico, 39 (1): 59-80.

HOFFMANN, Rodolfo (2006), “Transferências de renda e a redução da desigualdade no Brasil e cinco regióes entre 1997 e 2004 ". Revista Econômica, 8 (1): 55-81.

HOFFMANN, Rodolfo (2009), "Desigualdade da distribuição da renda no Brasil: a contribuição de aposentadorias e pensóes e de outras parcelas do rendimento domiciliar per capita”. Economia e Sociedade, 18 (1): 213-231.

HOFFMANN, Rodolfo (2017), "Desigualdade da distribuição da renda no Brasil: O que mudou em 2015?”. Instituto de Estudos de Política Econômica, Rio de Janeiro, Texto para Discussão no 38.

HOFFMANN, Rodolfo (2013), "Transferências de renda e desigualdade no Brasil (1995-2011)", in: T. Campello \& M. C. Neri (ed.) Programa Bolsa Família: uma década de inclusáo e cidadania. Brasília, IPEA.

HOFFMANN, Rodolfo (2010), "Desigualdade da renda e das despesas per capita no Brasil, em 2002-2003 e 2008-2009, e avaliação do grau de progressividade ou regressividade de parcelas da renda familiar". Economia e Sociedade, 19 (3): 647-661, dez. 2010.

HOFFMANN, Rodolfo (2014), "Transferências de renda e desigualdade, Brasil, 1995-2012: análise de 11 parcelas da renda domiciliar per capita”. Programa Bolsa Família: uma década de inclusáo e cidadania, IPEA.

HOFFMANN, Rodolfo (2014), "Fatos relevantes sobre a distribuição da renda no Brasil". 520 Congresso da SOBER, Goiânia.

HOFFMANN, Rodolfo \& OLIVEIRA, Regis Borges de (2012), "The evolution of income distribution in Brazil: different Characteristics of the agricultural sector", in: 28th Triennial Conference of the International Association of Agricultural Economists, 28, Foz do Iguaçu, Brasil. INSTITUTO BRASILEIRO DE GEOGRAFIA E ESTATÍSTICA (IBGE) (2016). "Pesquisa Nacional de Amostra por Domicílios - Volume Brasil”.
JESUS, Josimar Gonçalves de \& HOFFMANN, Rodolfo (2016), "Desigualdade de renda no Brasil: a contribuição de parcelas do rendimento domiciliar per capita, destacando o setor agrícola”. Congresso da Sober, Maceió, AL.

MARINHO, Emerson; LINHARES, Fabricio \& CAMPELO, Guaracyane (2011), "Os programas de transferência de renda do governo impactam a pobreza no Brasil?". Revista Brasileira de Economia, 65 (3): 267-288.

MARQUES, Rosa Maria (2013), "Políticas de transferência de renda no Brasil e na Argentina”. Revista de Economia Política, 33 (2): 298-314.

MELO, Maria Renata Bezerra \& MONTE, Paulo Aguiar do (2014), "Rendimentos e desigualdade de renda no Brasil: 2004-2012”. Revista Econômica, 16 (2): 115-131.

MINISTÉRIO DO DESENVOLVIMENTO SOCIAL E COMBATE À FOME - Benefício de Prestação Continuada.

IPEA. Ipeadata: base de dados sobre o coeficiente de Gini. Disponível em: <http://www.ipeadata.gov. br/>. Acesso em: 17 de set. de 2014.

OCDE. Relatórios Econômicos da OCDE Brasil, Novembro de 2015. Disponível em: <http://www. oecd.org/eco/surveys/Brasil-2015-resumo.pdf>.

OCDE. In it together: why less inequality benefits all, Maio de 2015. Disponível em: <http://www. oecd.org/social/in-it-together-why-less-inequalitybenefits-all-9789264235120-en.htm>.

OLIVEIRA, Rodrigo Carvalho \& SILVEIRA NETO, Raul da Mota (2016), "Expansão da Escolaridade e Redução da Desigualdade Regional de Renda no Brasil entre 1995 e 2011: progressos recentes e desafios presentes". Pesquisa e Planejamento Econômico, 46 (1): 41-65.

PAIVA, Luís Henrique; FALCÃO, Tiago \& BARTHOLO, Letícia (2013), "Do Bolsa Família ao Brasil sem Miséria: um resumo do percurso brasileiro recente na busca da superaçấo da pobreza extrema", in T. Campello\& M. C. Neri (ed.) Programa Bolsa Família: uma década de inclusão e cidadania. Brasília, IPEA.

PEÑA, Carlos Rosano; PINHEIRO, Danielle Sandi; ALBUQUERQUE, Pedro H. M. \& FERNANDES, 
Loyane Mota (2015), "A eficácia das transferências de renda: as tendências da desigualdade antes e depois do Programa Bolsa Família”. Revista de Administração Pública, 49 (4): 889-913.

RIBEIRO, Lilian Lopes; ARAUJO, Jair Andrade \& FEITOSA, Débora Gaspar (2015), "Crescimento pró-pobre? Uma análise para os meios urbano e rural no Brasil". Pesquisa e Planejamento Econômico, 45 (1): 155-176, abr. 2015. Disponível em: <http://ppe.ipea.gov.br/index.php/ppe/article/ view/1633/1173>. Acesso em: 03 abr. 2017.

ROCHA, Sonia (2011), “O programa Bolsa Família: evolução e efeitos sobre a pobreza”. Economia e Sociedade, 20 (1): 113-139.

SALATA, André (2016), "Inequalities and the Brazilian new democracy: income distribution between classes in recent decades". Sociologia Antropológica, 6 (1): 181-208.

SOARES, Fabio Veras; SOARES, Sergei; MEDEIROS, Marcelo \& OSÓRIO, Rafael Guerreiro (2006), "Programas de Transferências de renda no Brasil: impactos dobre a desigualdade”. Brasília: IPEA.

TAVARES, Priscilla Albuquerque; PAZELLO, Elaine Toldo; FERNANDES, Reynaldo \& CAMELO, Rafael de Souza (2009), "Uma avaliação do programa Bolsa Família: focalização e impacto na distribuição de renda e pobreza”. Pesquisa e Planejamento Econômico, 39 (1): 25-58.

THE WORLD BANK, World Development Indicators. Income Share Held By lowest 10\%, income share held by highest 10\%, 2016. 


\section{OS DETERMINANTES DA QUEDA DA DESIGUALDADE DE RENDA NAS REGIÓES BRASILEIRAS ENTRE 2001 E 2015}

\author{
Marina Guazzelli Saad, Adriana \\ Bruscato Bortoluzzo, Naercio Aquino \\ Menezes Filho e Bruno Kawaoka \\ Komatsu
}

Palavras-chave: Desigualdade de renda; Programas de transferência de renda; Índice de Gini.

Esse artigo busca sistematizar as explicaçôes para a queda da desigualdade de renda, ocorrida no Brasil entre 2001 e 2015 , analisando cada região e subperíodo separadamente, com foco nos programas sociais. Os resultados mostram que os rendimentos dos programas sociais e também as aposentadorias ganharam proeminência como fontes de renda em relaçáo à renda do trabalho. Os rendimentos dos programas sociais contribuíram com 19\% da redução da desigualdade de renda, especialmente no Norte e Nordeste, e nos períodos entre 2001-2004, e entre 2008-2012. Entretanto, sua contribuição diminuiu no Nordeste e aumentou no Sudeste, no início da grande recessão. Os rendimentos do trabalho contribuíram com $57 \%$ da queda da desigualdade e explicam por que ela caiu mais fortemente nas regióes Sul e Centro-Oeste. As aposentadorias e pensôes oficiais contribuíram com $17 \%$ da queda da desigualdade, atuaram em todas as regiôes do Brasil, e mais fortemente entre 2004 e 2012, período de grande aumento do salário-mínimo.

\section{INCOME INEQUALITY DECREASE DETERMINANTS IN BRAZILIAN REGIONS BETWEEN 2001 AND 2015}

\section{Marina Guazzelli Saad, Adriana Bruscato Bortoluzzo, Naercio Aquino Menezes Filho e Bruno Kawaoka Komatsu}

Keywords: Income inequality; Government income transfer programs; Gini Index.

This paper aims to systematize the explanations for income inequality decreases observed in Brazil between 2001 and 2015, analyzing each region and subperiod separately and focusing on social programs. The results indicate that social program incomes, as well as pension incomes, have gained prominence as income sources relative to labor income. Social program incomes contributed $19 \%$ to income inequality decreases, especially in the North and Northeast, between 2001-2004 and 2008-2012. However, this contribution declined in the Northeast and increased in the Southeast at the beginning of the great recession. Labor income contributed 57\% to income inequality decreases and explains why a sharper decrease was noted in the South and Center-West regions. Official pensions contributed $17 \%$ to inequality reductiomn in all Brazilian regions, more strongly between 2004 and 2012, when significant minimum wage increases occurred.

\section{LES DÉTERMINANTS DE LA CHUTE DES INÉGALITÉS DE REVENU DANS LES RÉGIONS BRÉSILIENNES ENTRE 2001 ET 2015}

\author{
Marina Guazzelli Saad, Adriana \\ Bruscato Bortoluzzo, Naercio Aquino \\ Menezes Filho e Bruno Kawaoka \\ Komatsu
}

Mots-clés: Inégalité des revenus; Programmes de transfert de revenus; Indice de Gini.

Cet article vise à systématiser les explications sur la baisse des inégalités de revenus survenues au Brésil entre 2001 et 2015, avec une analyse des programmes sociaux dans chaque région et à chaque sous-période. Les résultats montrent que les montants des programmes sociaux et des retraites sont devenus une source de revenu importante par rapport aux revenus d'activité. Entre 2001-2004 et 2008-2012, les sommes versées par les programmes sociaux ont ainsi diminué de 19\% les inégalités de revenus, en particulier dans le Nord et le Nord-est. Au début de la grande récession, cependant, elles ont été revues à la baisse dans le Nord-Est et à la hausse dans le Sud-est. Les revenus d'activité ont été responsables de $57 \%$ de la chute de l'inégalité, et plus spécialement dans le Sud et le Centre-Ouest. Quant aux retraites et pensions, elles ont participé à hauteur de 17\% de la baisse des inégalités dans toutes les régions du Brésil entre 2004 et 2012 surtout - période de forte augmentation du salaire minimum. 